University at Buffalo School of Law

Digital Commons @ University at Buffalo School of Law

\title{
"Private" Environmental Regulation, Human Rights, and Community
}

\author{
Errol E. Meidinger \\ University at Buffalo School of Law
}

Follow this and additional works at: https://digitalcommons.law.buffalo.edu/journal_articles

Part of the Environmental Law Commons

\section{Recommended Citation}

Errol E. Meidinger, "Private" Environmental Regulation, Human Rights, and Community, 7 Buff. Envtl. L.J. 123 (1999).

Available at: https://digitalcommons.law.buffalo.edu/journal_articles/551

\section{C) ${ }_{\text {COPYRIGHT }}^{\text {N }}$}

This Article is brought to you for free and open access by the Faculty Scholarship at Digital Commons @ University at Buffalo School of Law. It has been accepted for inclusion in Journal Articles by an authorized administrator of Digital Commons @ University at Buffalo School of Law. For more information, please contact lawscholar@buffalo.edu. 


\title{
"Private" Environmental Regulation, Human Rights, and Community ${ }^{H}$
}

\author{
(C) Errol E. Meidinger
}

Table of Contents

I. Introduction .......................... 125

II. The Forest Stewardship Council $\ldots \ldots \ldots \ldots \ldots \ldots \ldots$

A. Mission and Organization ................. 130

B. Program Elements ....................... 136

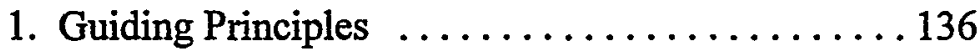

2. Certification ........................ 141

3. Logo ............................ 143

4. Chain of Custody ................... 143

5. Demand and Supply Promotion ............. 144

6. Environmental Management Systems .......... 147

7. Group Certification ................... 148

C. Program Operation $. . \ldots \ldots \ldots \ldots \ldots \ldots \ldots . \ldots . \ldots . \ldots 149$

1. Certification Patterns $\ldots \ldots \ldots \ldots \ldots \ldots . \ldots 149$

2. The Certification Process ................ 150

3. Regional and National Standard Setting ........ 155

\# This article grew out of a presentation prepared for the Human Rights, Environment, and Community Workshop in Buffalo, New York on April 18, 1998. The participants in that conference provided many helpful ideas and suggestions for the early development of the article. The final draft was greatly aided by the comments of Barry Boyer, Chris Elliott, Ira Feldman, Frank Munger, Margaret Shannon, and especially David Westbrook. It was completed in the friendly and stimulating environs of the Institute for Forestry Economics at the University of Freiburg, where a Fulbright Senior Scholar grant has allowed me to spend a very productive period. I thank all of the above most sincerely, but of course remain solely responsible for the remaining shortcomings of the article, some of which I hope to remedy in forthcoming publications.

Professor of Law and Co-Director, Environment \& Society Institute, State University of New York at Buffalo, <eemeid@buffalo.edu>, $<$ http://www.ublaw.buffalo.edu/fas/meidinger>. 


\section{BUFFALO ENVIRONMENTAL LAW JOURNAL [Vol 7}

D. Implications for Environment, Community, and Human Rights ....................... 164

1. Environment ........................ 165

2. Human Rights $\ldots \ldots \ldots \ldots \ldots \ldots \ldots \ldots \ldots \ldots, \ldots \ldots \ldots$

3. Community ..................... 174

III. The International Organization for Standardization $\ldots . . .183$

A. Mission and Organization .................. 183

B. Program Elements ...................... 186

1. Firm-Centered Environmental Policy .......... 186

2. Environmental Management System .......... 187

3. Continual Improvement ............... 192

4. Prevention of Pollution ................. 193

5. Auditing and Registration ................. 193

C. Program Operation ......................... 194

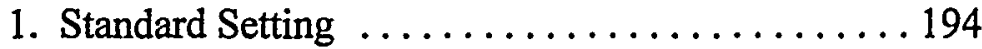

2. Certification Process .................... 198

D. Implications for Environment, Human Rights,

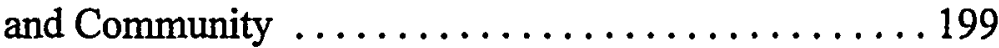

1. Environment .......................... 199

2. Human Rights $\ldots \ldots \ldots \ldots \ldots \ldots \ldots \ldots . \ldots 203$

3. Community .......................203

IV. The American Forest and Paper Association ......... 205

A. Mission and Organization .................. 205

B. Program Elements .....................206

1. Principles and Objectives ...............206

2. Management Defined Policy ............... 209

3. Verification .........................209

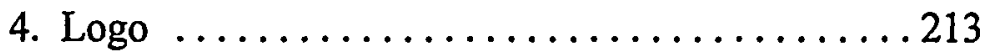

5. Logger Training ....................213

6. Licensing ............................ 214

7. Expert Review Panel ................... 214

C. Program Operation .......................216

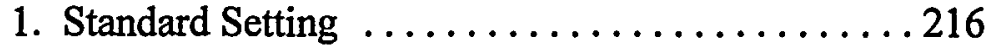

2. Verification ...................... 217 
D. Implications for Environment, Human Rights, and Community ........................ 217

V. Conclusions. .............................. 219

A. Patterns of Private Environmental Regulation ...... 219

B. Causes of Private Environmental Regulation ........ 222

C. Prospects of the Private Environmental

Regulatory Programs .................... 225

D. Important Questions $\ldots \ldots \ldots \ldots \ldots \ldots \ldots \ldots 228$

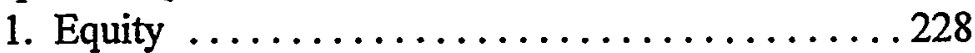

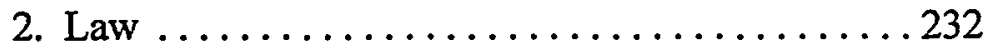

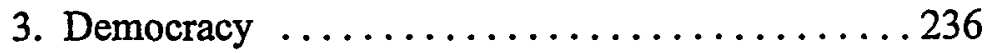

\section{Introduction}

Private organizations have recently established numerous programs aimed at improving the environmental performance of industry. Many of the new programs seek to define and enforce standards for environmental management, and to make it difficult for producers not to participate in them. They claim, explicitly and implicitly, to promote the public interest. They take on functions generally performed by government regulatory programs, and may change or even displace such programs. Private environmental regulatory programs thus have the potential to significantly reshape domestic and international policy institutions by changing the locus, dynamics, and substance of policymaking.

The expansion of private environmental regulation comes at a time of growing agreement that environmental goals must be integrated and pursued in tandem with social and economic ones. The primary source of this view is the worldwide movement for "sustainable development," catalyzed and given momentum by the United Nations Conference on Environment and Development in Rio in 1992.' Government programs to date have a relatively weak record of defining and pursuing sustainable development. Thus the growth

See infra note 29 and accompanying text. 
of private regulatory programs offers fresh hope by creating new institutional arenas in which sustainable development may be defined and implemented. At the same time, by expanding the arena of action and potentially changing the rules of engagement, private regulation also has the potential to deflect the movement for sustainable development.

With these possibilities in mind, this article reviews three private environmental regulatory programs:

-- the Forest Stewardship Council's forest and forest product certification program (FSC)

- the International Organization for Standardization's "ISO 14000 " program

-- the American Forest and Paper Association's Sustainable Forestry Initiative (AFPA).

The goals of this article are three. The first is to bring these programs to the attention of legal scholars and practitioners, who tend to be more familiar with governmental regulatory programs than private ones. The second goal is to provide a preliminary assessment of the programs' implications for the tripartite agenda of sustainable development. To make this task more tractable, the social dimension of sustainable development is analyzed in terms of human rights and community protection, constructs sufficiently familiar in legal scholarship to provide workable analytical categories. ${ }^{2}$ Finally, the article seeks to locate the programs in the larger context of social policy by describing several difficult questions of equity, law, and democracy that the programs will have to face if they are to continue to advance.

2 The economic dimension of sustainable development, the primary focus of most private organizations, is treated largely in terms of its relationship to environment, human rights, and community in this article. 
This article analyzes programs applicable to forestry. ${ }^{3}$ Forestry is the industry for which environmental certification programs appear most organizationally developed, and can be most meaningfully studied ${ }^{4}$ It is a major industry in both developed and developing countries, and often links them economically. Forest management is critical both to local environmental conditions, such as water quality and wildlife habitat, and to global environmental conditions, such as climate stability. Forestry involves the control of valuable resources and the doing of difficult and dangerous work, both of which often give rise to human rights issues. Forests provide the primary material and symbolic context for many place-based communities, especially for indigenous ones; how forests are managed can deeply affect daily life. Finally, forest management necessarily extends over long time periods. Alternative choices about how to manage forests can imply radically different futures for communities and their relationships to the environment.

The FSC is particularly arresting. The diminutive organization seeks to integrate environmental, human rights, community and economic goals in a consistent set of substantive standards on a global scale and to implement them. It pursues these goals in confidence that widely accepted principles and growing consumer demand can leverage them into practice. The ISO program also operates on a global scale, but does not set substantive standards nor seek to integrate environmental, human rights, and community goals. Instead, it uses environmental management systems to seek continuous improvement in environmental performance, and applies

3

It is important to note that the ISO program is also applicable to many other industries.

4 There is a huge and growing array of environmental certification programs in the world, focusing on everything from organic food to coffee beans to ecotouristry programs and everything in between. The programs discussed in this article are among the most interesting, and perhaps institutionally significant, because they seek to shape industrial management practices systematically by promulgating law-like texts to define management standards for industries and to organize their operations. 
to a wide array of industries. The AF\&PA program is limited to forest-products companies in a single nation and does not link environmental to human rights and community goals, but it counters the other programs by defining competing substantive standards and staking out an independent role for large American forestry companies. It has important counterparts in a number of other countries, including Canada and Indonesia, and has recently been matched and raised by the emergence of a "pan-European" certification program. $^{5}$

Because of their novelty and relative obscurity in legal scholarship, the three programs are described in substantial detail in this article. Thus, readers who are already knowledgeable or who do not seek detailed information will want to skim some sections. The FSC program is examined most thoroughly. The ISO and AF\&PA programs are described somewhat more briefly by comparison and contrast to the FSC program.

5

A recent report lists a dozen national forestry certification programs operating in Bolivia, Brazil, Canada, Finland, Germany, Ghana, Indonesia, Malaysia, Norway, Sweden, the UK, and the USA. See Stephen Bass \& Markku Simula, Independent Certification/Verification of Forest Management, November 29, 1999, at 11 (background paper prepared for the World Bank/WWF Alliance Workshop, Washington, D.C., November 9-10, 1999) <http://wwwesd.worldbank.org/wwf/sim-bass.doc $>$ (on file with author). An earlier report also listed significant national efforts in Belgium, Portugal, and Spain. See Dietrich Burger \& Barbara Von Kruedener, Forest Certification - Status Report and Overview (February 1998) (report of the Forest Certification Project, Deutsche Gesellschaft fur Technische Zusamenarbeit (GTZ - German Organization for Technical Cooperation, Eschborn, Germany)) (on file with author). Most of the national programs are off-shoots of the FSC movement or responses to it, but they all seek to define distinctive national approaches to forest certification. Perhaps most significantly, the Pan-European Forest Certification Council (PEFC) was founded in mid-1999. It seeks to link national certification programs in European countries within a more general framework based on common standard setting, third-party auditing, certification procedures, and certifier accreditation requirements. While the PEFC program will clearly be an important force in coming forest certification developments, it is too new and relatively unformed to be analyzed in this article. See generally <http://www.pefc.org/content.htm>. 
The programs share many important patterns. They use lawlike texts to organize their own missions and behavior, as well as those of certifiers and certified organizations. They assume that their programs can achieve legitimacy based on a commitment to widely accepted principles implemented by professionals working in a market framework. And they assume that requiring firms to produce and analyze information on their environmental performance will lead to organizational learning and improved performance, even if that information is not shared with the public or regulatory agencies. Finally, they rely heavily on preexisting social and economic networks to amplify their credibility.

The article concludes, among other things, that each of the programs has some potential for improving the environmental performance of forest enterprises, but that only the FSC program offers much hope of strengthening the protection of human rights and the participation of communities in forest management. Indeed the ISO and AF\&PA programs seem designed to narrow the human rights concerns that firms must take into account, and to dampen the participation of communities by helping firms to "manage" community concerns more effectively. If one program were to prevail it would likely be the ISO program, based on its superior organizational and financial resources. However, rather than being entirely separate, these and other programs compete with and complement each other in a larger regulatory arena. It is possible that one or more hybrids combining elements of several programs will emerge over time.

The conclusion also argues that the private regulatory programs pose some pressing questions for societal institutions. First are those of equity and fairness. Many of the benefits of certification programs have thus far accrued largely to organizations based in developed countries. Developed countries have also dominated the development and standard setting processes in certification programs. The certification programs will have to successfully address equity questions if they hope to gain worldwide legitimacy. 
Second, certification programs pose important challenges for traditional legal systems. Because the programs establish independent standard setting and enforcement processes, legal systems will have to decide how to deal with them. Regardless of how legal systems react, substantive legal standards are likely to be affected by certification systems over time, as private standards suffuse public ones through environmental regulation, tort law, financial regulation, and other avenues. It is also possible that, where certification systems appear to improve the performance of firms, legal systems will reallocate regulatory resources to other areas. Certification systems may also create conflicts with some legal policies, particularly in the area of trade law, and could be subjected to legal regulation over time.

Finally, the rise of certification systems may imply challenges for conventional definitions of democratic governance. Certification programs move policy making away from governmental and intergovernmental organizations and toward non-governmental ones. They claim democratic legitimacy based on a combination of expertise, commitment to widely accepted but poorly defined principles, and participation processes in which they select the participants. At the same time they tend to internationalize policymaking. If certification systems prove durable and come to be widely treated as legitimate, they may contribute to a significant redefinition of democratic policymaking.

\section{The Forest Stewardship Council}

\section{A. Mission and Organization}

The Forest Stewardship Council (FSC) was founded in 1993 "to promote environmentally responsible, socially beneficial and economically viable management of the world's forests, by establishing a worldwide standard of recognized and respected 
Principles of Forest Management. ${ }^{16}$ The mission is highly ambitious. It seeks not only to combine environmental, social and economic criteria in the same standard, but also to do so worldwide, thereby covering very different tropical, temperate, and boreal forests and the people who live in and near them. ${ }^{7}$ To establish its standard the FSC is building a freestanding, market-driven certification system. The system will certify both forests and the products that come from them.

The FSC has its direct origins in discussions among a group of small-scale North American furniture makers, the Woodworkers' Alliance for Rain Forest Protection (WARP), who became concerned about the effects of their exotic hardwood use on tropical rain forests in the late 1980s. By 1990 they had concluded that a system was needed for certifying sustainably produced tropical hardwoods, and that it should be established by environmentalists as quickly as possible. The idea of a certification system, presumably run by governmental organizations, had already been proposed to the International Tropical Timber Organization (ITTO), an intergovernmental organization charged with developing national policies for protecting tropical forests. ${ }^{8}$ But it had been resisted by

6 Forest Stewardship Council Principles and Criteria for Forest Management $<$ http://www.fscoax.org/principal.htm> [hereinafter FSC Principles and Criteria]. 7 When the FSC was founded its mission included certifying "sustainably managed forests." The FSC has since retreated from the proposition that it can certify sustainable management on grounds that it might suffer a loss of credibility if some certified forests in fact turned out over time not to be sustainable. It has therefore adopted the term "well-managed forest," with the intent of applying it so as to achieve sustainable management. Personal communication.

This citation reflects the fact that research for this article was based partly on personal interviews with participants and knowledgeable observers of the processes involved. Because not all interviewees agreed to speak for personal attribution, interview based information is cited as "personal communication." 8 See Chris Elliott, Forest Certification: Analysis from a Policy Network Perspective 103 (1999) (unpublished Ph.D. Thesis, École Polytechnique Fédérale De Lausanne) [hereinafter Elliott, Forest Certification].

The ITTO was established by the International Tropical Timber 
some members as possibly a disguised way of boycotting tropical timber, and by others as simply unworkable.

Meanwhile many environmental organizations concluded that the ITTO process had been a failure that would not yield significant improvements in tropical forest management in an acceptable time frame. Thus, they adopted and promoted the WARP proposal for a non-governmental certification scheme. ${ }^{9}$ The World-Wide Fund for Nature (WWF), a major international environmental NGO dedicated to the protection of nature and biological diversity, ${ }^{10}$ became the primary promoter of forest certification. Together with the MacArthur Foundation, the WWF put significant resources behind the project, resulting in the founding of the FSC in Toronto in 1993. The WWF thus invested in establishing what it hoped would be a distinct, durable institutional framework, after which it continued with its varied activities as a general purpose environmental NGO."

Agreement of 1983, which was negotiated under the auspices of the United Nations Conference on Trade and Development. One of its objectives was:

To encourage the development of national policies aimed at sustainable utilization and conservation of tropical forests and their genetic resources, and at maintaining the ecological balance in the region concerned. $§ 1(\mathrm{~h})$. 9 See Elliott, Forest Certification, supra note 8, at 107.

10 See WWF Website <http://www.wwf.org/>. WWF International was founded in 1961. National subsidiaries soon followed in the US and UK. It gradually evolved from an organization devoted to preserving somewhat exotic wildlife and places to one focusing on nature and biodiversity generally. WWF International now has an operating budget of over $\$ 50,000,000$. $<$ <ttp://www.panda.org/wwf/Report98/accounts.html> . Its four major national groups have comparable budgets, and its more than twenty smaller national groups also appear prosperous. The organization is known as the World Wildlife Fund in the U.S. and Canada.

$1 \quad$ See Claude Welch, Human rights, environment and the Ogoni: Strategies for non-governmental organizations, infra $\mathrm{p} .251$ this volume, for an overview of the common types of activities of NGOs. 
The FSC now has over 300 members from over 45 countries. ${ }^{12}$ The members are mostly organizations, but also include a growing number of individuals. ${ }^{13}$ The FSC has no official ties to government agencies, and indeed prohibits them from membership. ${ }^{14}$ The organization accepts government funding on condition that it not be tied to any restrictions that would affect its independence, ${ }^{15}$ and has accepted a considerable amount over the years, mostly from European governments. ${ }^{16}$

According to its Executive Director, the "FSC is not an Environmental NGO. FSC operates as a multi-stakeholder organization, building the interests of all main stakeholder groups into forest management standards and certification." ${ }^{17}$ The political

12. List of FSC Members, FSC Doc. 5.2.2. (October 1999) $<$ http://www.fscoax.org/html/5-2-2.html >

13 See id.

14 See FSC Statutes, Seventh Art. <http://www.fscoax.org/html/1-3.htm>. Members of government agencies have participated in at least some regional and national standard setting processes, however, often as technical experts. See e.g., Process for Developing FSC Standards for the Maritime Forest Region (visited May 26, 1999) <http://www.canadian-forests.com/fsc-process.html> [hereinafter Maritime Process] (on file with author). The International FSC voted in its second general assembly in June 1999 to examine options for involvement in the FSC by public sector forest managers who are undergoing certification. See Draft Minutes of the Forest Stewardship Council General Assembly, Oaxaca, Mexico, June 2425,1999, Motion $5<\mathrm{http}: / / \mathrm{www} . \mathrm{fscoax} .0 \mathrm{rg} / \mathrm{html} /$ assembly_general/fscgamin.htm> [hereinafter FSC Draft Minutes].

is See Forest Stewardship Council A.C. By-Laws, FSC Doc. 1.1 (Ratified, September 1994; Editorial Revision, October 1996; Revised February 1999). "FSC will accept contributions from non-governmental organizations, foundations, government sources, multilateral agencies and individuals, as long as no restrictions are attached which would affect the independence or integrity of FSC." <http://www.fscoax.org/html/1-1.html >.

16 See Chris Elliott\& Arlin Hackman, Current Issues in Forest Certification, in CANADA: A WWF CANADA DISCUSSION PAPER 5 (1996).

17 Tim Synott, Forest Stewardship Council, $A C$, in DEFINING A FOREST VISION: WORLD WILDLIFE FUND'S NORTH AMERICAN FORESTS FOR LIFE CONFERENCE (Kathleen Kessler et al. eds., 1998). 
theory of the FSC can thus be described as "representative participation." The assumption is that if the proper stakeholders are represented and participate in decision-making processes, then good and legitimate decisions will result. ${ }^{18}$

Although it is organized as a not-for-profit corporation, the FSC's structure resembles that of a federalist constitutional government with formalized corporatism. ${ }^{19}$ Its central decisionmaking body, the General Assembly, is organized into three chambers, "environmental," "social," and "economic," with equal voting power; thus, at least two of the chambers must concur in any decision. ${ }^{20}$ Each chamber is further subdivided into a Northern subchamber, for members from developed countries, and a Southern subchamber, for members from developing countries. Each subchamber has half the chamber's total voting power. ${ }^{21}$ Membership in the FSC is by application to the FSC. In other words, the FSC

18

E.g., Kirsti Thornber et al., Certification: Barriers to Benefits: A Discussion of Equity Implications, at 17 (Eur. Forestry Inst. Discussion Paper No. 8,1999 ) [hereinafter Thomber, Equity and Certification] (on file with author).

19 Corporatist systems are defined as formally integrating major interest groups into their political decision-making processes. See DAVID HELD, MODELS OF DEMOCRACY (1987). The best known examples are European states, where labor unions, producer organizations and governments have often negotiated key policies. See PATTERNS OF CORPORATIST POLICY-MAKING (Gerhard Lehmbruch \& Philippe C. Schmitter, eds., 1982).

20 See Forest Stewardship Council Statutes $<$ http://www.fscoax.org/principal.htm>. Membership was originally divided into an economic chamber with $25 \%$ of the voting power and an environmental-social chamber with $75 \%$. The tri-partite arrangement was adopted in 1996, after considerable criticism from industrial and commercial interests.

21 The subchambers are an effort to compensate for a low level of representation from developing countries. As of September 1999, membership stood as follows:

Economic Chamber: 124 members, $30(24 \%)$ from the South.

Environmental Chamber: 137 members, 41 (43\%) from the South.

Social Chamber: $\quad 52$ members, $14(27 \%)$ from the South.

See Thornber, Equity and Certification, supra note 18, at 34.

The low overall level of membership in the Social Chamber is also noteworthy. 
selects the members allowed to represent each type of interest in its central governing body. ${ }^{22}$ The FSC has also begun to focus on "national initiatives" "to decentralize the work of the FSC and to encourage local participation. ${ }^{123}$ It might thus be seen as gradually building a federalist structure.

The FSC's operational authority is vested in a nine member Board of Directors, who are elected to staggered three-year terms by the General Assembly. Two members of the Board are from the economic chamber; the other seven are from the environmental and social chambers. ${ }^{24}$ The Board is responsible for managing the organization, dispersing its budget, provisionally admitting members, and a host of other activities ${ }^{25}$ that, while nominally ministerial, play a large role in shaping the policies of the organization. The daily work of the FSC international office is carried out by a Secretariat of approximately a dozen individuals headed by an executive director and headquartered in Oaxca, Mexico. ${ }^{26}$ Their 1998 budget was approximately $\$ 1.2$ million U.S. ${ }^{27}$

22 Applications can be accepted by the Board of Directors, but are subject to challenge in the General Assembly. See FSC Statutes, Title Two, Secs. Seven and Eight <http://www.fscoax.org/html/1-3.htm>.

23 FSC Protocol for Endorsing National Initiatives, FSC Doc. 4.1 (February 1998)<http://www.fscoax.org/html/4-1.html>.

${ }^{24}$ See id. at Sec. Eighteen.

25 See id.

26 See Address List for FSC Directors and Secretariat, FSC Doc. 5.1.1. (November 1999) <http://www.fscoax.org/html/5-1-1.html . The FSC also has a Technical Committee which reviews and makes recommendations to the Board on matters such as the development of national and regional standards, an Accreditation Committee, which reviews the applications of certification bodies and proposes conditions of acceptance to the Board, a Dispute Resolution Committee, and a growing group of regional representatives.

$27 \quad$ See Klas Sander, Transaction Costs and Forest Certification in Germany (1999) (unpublished M.Sc. Thesis, Wye College, University of London). Information on the total budgets of the national and regional programs was not available at the time of this writing. 


\section{B. Program Elements}

\section{Guiding Principles}

The FSC program is oriented around ten overarching principles. ${ }^{28}$ The Principles were developed and adopted early in FSC's history, in 1994, when it was a relatively small organization made up largely of environmentalists from Europe and North America. The Principles are treated as self-evidently legitimate, which is not entirely surprising, since they express gospel-like verities that have emerged from a variety of processes in the worldwide discussion on sustainable development. ${ }^{29}$ They

FSC Principles and Criteria, supra note 6.

29 "Sustainable development" was most memorably defined by the Brundtland Commission in 1987 as "development that meets the needs of the present without compromising the ability of future generations to meet their own needs." WORLD COMMISSION ON ENVIRONMENT AND DEVELOPMENT, OUR COMMON FUTURE 43 (1987). In the worldwide dialogue on sustainable development since then it has gradually come to be understood as having a fundamental commitment to fusing the often separated goals of environmental protection, economic development, and social equity. E.g., John Dernbach et al., U.S. Adherence to Its Agenda 21 Commitments: A Five-Year Review, ENVTL. L. REP. (Envtl. L. Inst.) 10,504, 10,507 (1999); J.B. Ruhl, The Seven Degrees of Relevance: Why Should Real-World Environmental Attorneys Care Now about Sustainable Development Policy?, 8 DUKE ENVTL. L. \& POL'Y F. 273 (1998).

Delegates to the Rio Conference in 1992, officially known as the United Nations Conference on Environment and Development (UNCED), adopted the "Non-Legally Binding Authoritative Statement of Principles for a Global Consensus on the Management, Conservation and Sustainable Development of All Types of Forests," basically describing sustainable forest management as a good idea which they would pursue. They also adopted "Agenda 21," in which the governments agreed to cooperate with interest groups and other international organizations in formulating "scientifically sound criteria and guidelines for the management, conservation and sustainable development of all types of forests." Agenda 21, Ch. 11, Sec. 11.22(b). For a thoughtful analysis of these documents and their implications for international policy institutions, see Lee P. Breckenridge, Protection of Biological and Cultural Diversity: Emerging Recognition of Local Community Rights in Ecosystems Under International Environmental Law, 59 
are also quite general, so that their meaning must be worked out in more concrete processes of standard setting and certification. The Principles are as follows (emphasis added):

1. Forest management shall respect all applicable laws of the country in which they occur, and international treaties and agreements to which the country is a signatory, and comply with all FSC Principles and Criteria.

2. Long-term tenure and use rights to the land and forest resources shall be clearly defined, documented and legally established.

3. The legal and customary rights of indigenous peoples to own, use and manage their lands, territories, and resources shall be recognized and respected.

4. Forest management operations shall maintain or enhance the long-term social and economic wellbeing of forest workers and local communities.

5. Forest management operations shall encourage the efficient use of the forest's multiple products and services to ensure economic viability and a wide

TENN. L. REV. 735 (1992).

The United Nations established a Commission for Sustainable Development in 1993, "to review progress . . . in the implementation of recommendations [by] ... the United Nations Conference on Environment and Development (UNCED), . . to elaborate policy guidance and options for future activities to follow up UNCED and achieve sustainable development, [and] to promote dialogue and build partnerships for sustainable development with governments, the international community and the major groups identified in Agenda 21 as key actors outside the central government who have a major role to play in the transition towards sustainable development including women, youth, indigenous peoples, non-governmental organizations, local authorities, workers and trade unions, business and industry, the scientific community, and farmers." $<$ http://www.un.org/esa/sustdev/csdback.htm>. 
range of environmental and social benefits.

6. Forest management shall conserve biological diversity and its associated values, water resources, soils, and unique and fragile ecosystems and landscapes, and, by so doing, maintain the ecological functions and the integrity of the forest.

7. A management plan -- appropriate to the scale and intensity of the operations -- shall be written, implemented, and kept up to date. The long term objectives of management, and the means of achieving them, shall be clearly stated.

8. Monitoring shall be conducted -- appropriate to the scale and intensity of forest management -- to assess the condition of the forest, yields of forest products, chain of custody, management activities and their social and environmental impacts.

9. Management activities in high conservation value forests shall maintain or enhance the attributes which define such forests. Decisions regarding high conservation value forests shall always be considered in the context of a precautionary approach. ${ }^{30}$ secondary forests and sites of major environmental, social or cultural significance shall be conserved. Such areas shall not be replaced by tree plantations or other land uses." It was changed in early 1999 to allow for the possibility of logging in those forests in appropriate cases. What kind of logging will be allowed in "high conservation value forests" must now be worked out. The term is defined as follows in the FSC glossary:

High Conservation Value Forests are those that possess one or more of the following attributes:

a) forest areas containing globally, regionally or nationally significant : concentrations of biodiversity values (e.g. endemism, endangered species, refugia); and/or large landscape level forests, contained within, or containing the management unit, where viable populations of most if 
10. Plantations shall be planned and managed in accordance with Principles and Criteria 1 - 9, and Principle 10 and its Criteria. While plantations can provide an array of social and economic benefits, and can contribute to satisfying the world's needs for forest products, they should complement the management of, reduce pressures on, and promote the restoration and conservation of natural forests. ${ }^{31}$

not all naturally occurring species exist in natural patterns of distribution and abundance

b) forest areas that are in or contain rare, threatened or endangered ecosystems

c) forest areas that provide basic services of nature in critical situations (e.g. watershed protection, erosion control)

d) forest areas fundamental to meeting basic needs of local communities (e.g. subsistence, health) and/or critical to local communities' traditional cultural identity (areas of cultural, ecological, economic or religious significance identified in cooperation with such local communities).

FSCPrinciples and Criteria, FSCDoc. $1.2<\mathrm{http}: / / \mathrm{www}$.fscoax.org/html/1-2.html $>$.

31 The terms are defined as follows:

Natural Forest: Forest areas where many of the principal characteristics and key elements of native ecosystems such as complexity, structure and diversity are present, as defined by FSC approved national and regional standards of forest management.

Plantation: Forest areas lacking most of the principal characteristics and key elements of native ecosystems as defined by FSC-approved national and regional standards of forest stewardship, which result from the human activities of either planting, sowing or intensive silvicultural treatments. 
These Principles are accompanied by "criteria" intended to clarify their application. Thus, Principle 6, on conserving biological diversity, is followed by ten criteria. An example is Criterion 6.2:

Safeguards shall exist which protect rare, threatened and endangered species and their habitats (e.g., nesting and feeding areas). Conservation zones and protection areas shall be established, appropriate to the scale and intensity of forest management and the uniqueness of the affected resources. Inappropriate hunting, fishing, trapping and collecting shall be controlled. $^{32}$

While this criterion does flesh out the principle somewhat, it still requires considerable interpretation. What are sufficient safeguards to protect endangered species? What is an appropriate conservation zone? What is inappropriate hunting? And so on. Clearly, considerable judgment and policymaking will be involved in applying these terms.

The Principles and Criteria are given further meaning in two types of policy processes. The first, on which the FSC's literature focuses, is the development of national and regional standards and indicators. National standards are to be developed for smaller countries with relatively homogenous forests, while regional standards are for large countries with highly diverse forest situations, such as the USA, Canada, and Mexico. Many regional and national standard-setting processes are underway as this is written, and some are discussed below. ${ }^{33}$ Few have been completed, however. The second process of standard definition is the actual process of

FSCPrinciples and Criteria, FSC Doc. $1.2<\mathrm{http} / / \mathrm{www} . \mathrm{fscoax} .0 \mathrm{rg} / \mathrm{htm} / \mathrm{l}$ 2.html>.

33 See supra text accompanying notes 94 through 125 . 
certification. An enormous amount of land has been certified in the absence of governing national or regional standards and indicators, meaning in practice that certifiers and applicants work out the meaning of the Principles and Criteria on the ground.

\section{Certification}

\section{a) of Forests}

To be certified, forests must meet the FSC Principles and Criteria and any applicable regional or national standards. Until regional or national standards are approved, forests can be certified based entirely on the Principles and Criteria. The certification is conducted by an FSC accredited, third-party certifier. The certifier is in charge of monitoring and re-accreditation as well. Costs of certification are borne by the forest enterprise, although many companies, particularly in developing countries, have received financial assistance. The certification process is described further below. ${ }^{34}$

\section{b) of Certifiers}

The FSC does not certify forests. Rather, it certifies certifiers, who in turn certify forests and "chains of custody" for the products that come from them. ${ }^{35}$ There are currently six FSC-approved certification organizations, two in the United Kingdom, two in the United States, and one each in the Netherlands and Switzerland. ${ }^{36}$ The certifiers are essentially consulting firms, often with operations in many countries. Most of them also are accredited to provide certification under other systems, including the ISO. Four of the FSC

\footnotetext{
$34 \quad$ See supra text accompanying notes 61 through 93.

35 See Synnot, supra note 17 , at $\mathrm{xx}$.

36 See FSC Accredited Certification Bodies, FSC Doc. 5.3.1 (July 1999)

$<$ http://www.fscoax.org/html/5-3-1.html $>$.
} 


\section{BUFFALO ENVIRONMENTAL LAW JOURNAL [Vol 7}

accredited certifiers are for-profit organizations, and two are not-forprofit. Approximately ten applications from certifiers are pending with the FSC as this article is published. All but one are European or North American companies; the other is South African. ${ }^{37}$

Although the FSC references certain general criteria, such as compliance with the Principles and Criteria, "independence from government or timber influence," and "sound evaluation procedures, "38 its procedures for accrediting certifiers do not appear transparent to the outside world. They seem to have varied with individual cases, although the FSC now appears to be standardizing the accreditation process. ${ }^{39}$ Certifiers are expected to maintain "complete transparency and openness to scrutiny by the FSC," and are subject to renewal review at least every five years. ${ }^{40}$

37 See FSC Applicant Certification Bodies, FSC Doc. 5.3.2 (November 1999) <http://www.fscoax.org/html/5-3-2.html>. One researcher estimates that it costs a certifier approximately $\$ 13,000$ to $\$ 16,000 \mathrm{US}$ to achieve certification, and that it costs FSC International approximately the same amount to conduct the certification review. See Sander, supra note 27. Personal interviews suggest that these estimates may be too low.

38 CHRISTOPHER UPTON \& STEPHEN BASS, THE FOREST CERTIFICATION HANDBOOK 189 (1995).

39 FSC has produced a $200+$ page manual on accreditation procedures, but it still contains relatively little information on what the substantive standards for accreditation are. See M.G. Wenban-Smith, et al., FSC Accreditation Manual, FSC Doc. 3.1 (January 1998). 


\section{Logo}

Products produced from and traceable to certified forests are entitled to carry the FSC logo, a somewhat deciduous looking conifer which merges with a check mark and is bottomed on the letters "FSC."

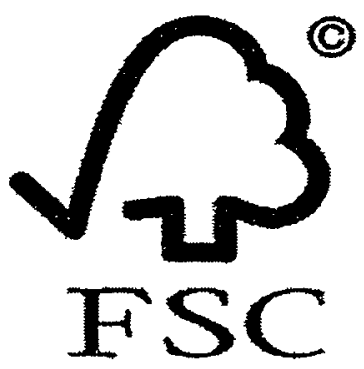

\section{Chain of Custody}

Because the system is driven in significant part by the FSC logo on products, companies seeking to use it must achieve certification of a "chain of custody" from primary production through retail sale. Conceptually, this could require either that every wood product be traceable to a particular forest, or that manufacturers of certified products deal exclusively with certified producers or with intermediate dealers who deal only with certified producers. For large, diversified firms, particularly those buying and selling in multiple markets, these requirements could be very onerous. On the other hand, the legitimacy of the certification system depends on consumer confidence that labeled products derive from forests meeting FSC standards. Accordingly, the chain of custody requirement has been a difficult and contentious issue for the FSC. 
At present it has come to rest on a policy that requires solid wood products to come entirely from certified forests, but allows up to $30 \%$ of composite products, such as paper and chip products, to come from non-certified lands. ${ }^{41}$

\section{Demand and Supply Promotion}

For the FSC certification system to work, consumers must want and be able to find certified products. WWF and environmental groups have taken a number of steps to build effective demand. First, they have done a considerable amount of advertising, particularly in media aimed at "cultural creatives," whom they believe can relatively easily be persuaded to seek and buy certified products. ${ }^{42}$ Second, they have promoted establishment of "buyers groups" composed of wholesale and retail forest products dealers who commit themselves

See FSC Policy on Percentage-Based Claims, FSC Doc. 3.6.3, (Revised February 24, 1999) <http://www.fscoax.org/principal.htm>. Paper and fiber products may contain up to $75 \%$ recycled products and receive certification so long as at least $70 \%$ of the remainder comes from FSC certified sources. For products with lower recycled content there is a sliding scale. For example, a product with $50 \%$ recycled content must have at least $35 \% \mathrm{FSC}$ endorsed virgin wood fiber, thus allowing up to $15 \%$ non-certified fiber. Id.

Personal communications. One interviewee put the strategy very clearly:

What we're shooting for is what some people call the "cultural creatives," . . folks that are aware of the ecological impacts of their purchasing, the ones that look for the stamp of the dolphin friendly tuna on the shelf. And it's a rather large portion of the country.... Something like 10 percent of the nation's population is within the cultural creative category. And if we can reach that 10 percent then this whole thing will really take off. Even though we don't have to get out the rest of society, ... I think the cultural creatives can pull a lot of other folks along with them. And so that's the strategy, is to launch an education campaign that's aimed at the cultural creatives. 
to buying only certified products as of a certain date ${ }^{43}$ The first and still the most significant is the U.K. "1995+ Group," which is said to account for approximately $15 \%$ of the demand for wood products in the U.K. at present, ${ }^{44}$ and for over $25 \%$ of retail sales. ${ }^{45}$ Buyers groups have also been established in Australia, Austria, Belgium, Brazil, Germany, Greece, Ireland, Japan, Netherlands, Norway, Spain, Sweden, Switzerland, the United Kingdom, and the United States. ${ }^{46}$ Third, environmental groups have put pressure on major retailers to carry FSC certified products, which in turn has put pressure on their suppliers to produce them. ${ }^{47}$ Environmental groups have occasionally organized demonstrations outside retail outlets of companies they believe are not moving quickly enough. ${ }^{48}$ Whether due to this

43 Some of these groups have specified FSC certification. But because of trade law concerns, they are likely simply to specify certification to comparable standards.

$44 \quad$ See $<$ http://www.panda.org/forests4life/forestmaps/95stats.htm>.

45 See Elliott, Forest Certification, supra note 8, at 25.

46 See FSCBuyers Groups: Contact Details $<$ http://www.fscoax.org $/ \mathrm{html} / 5-$ 3-6.html .

47 The UK building supply chain, B\&Q, with $19 \%$ of that country's retail building supply market, adopted a policy of commitment to sustainably produced timber almost a decade ago, when some sectors of the environmental movement momentarily undertook a tropical timber boycott. $B \& Q$ recently promised that "by the end of $1999, B \& Q$ will only purchase timber based products from forests independently certified by a certifier accredited by the Forest Stewardship Council." <http://www.b-and-q.co.uk/about_us/environment/au_e_timber.jsp>.In 1997 B\&Q announced cancellation of a $\$ 1-2$ million contract with MacMillan Bloedel, the largest forest products company in British Columbia, due to a failure of Macmillan Bloedel to demonstrate progress toward FSC certification. Six months later, in a major turnabout, Macmillan Bloedel announced that its policy was to meet the standards of all existing forest certification programs. See Elliott, Forest Certification, supra note 8, at 432.

48 Home Depot, an American firm which is the world's largest wood retailer, has also long advertised its efforts to sell sustainably produced timber, and recently committed not to buy timber from endangered forests anywhere in the world. $<$ http://www.homedepot.com $>$. The company has been under continuing pressure from the Rainforest Alliance to do better, however, and its stores have been subjected to a number of demonstrations throughout North America over the past 
pressure or not, there are many anecdotal testimonials to their influence and to business fears of bad publicity. Some of the best evidence may be the growing number of firms that are scrambling to address potential questions of certification by obtaining either FSC or another form of certification. ${ }^{49}$ WWF has also worked to create financing for production of certified timber in poor countries. In 1997 it announced a joint program with the World Bank to assist developing countries to bring 200 million additional hectares under certification by $2005 .^{50}$ Regarding consumer demand at the retail level, there is some indication of substantial demand for certified products in Europe, and growing but more limited demand in North America. ${ }^{51}$ There is considerable uncertainty whether producers adopt certification primarily to gain higher prices (a "green

year. The company's response is that there simply isn't enough certified wood available to supply all of its operations. See Janet Wilson, Uneasy Partnerships Form over Environmental Issues, L.A. TIMES, July 18, 1999 [hereinafter Wilson, Uneasy Partnerships].

49 See, e.g., Dean Starkman, International Paper Hires Consultant To Assess Forest-Management Practices, WALL ST. J., November 24, 1999, at A8 (reporting on decisions by International Paper Company and a number of other forest products companies to have their lands certified). IP chose to certify to the AF\&PA standard discussed below, but also to use an optional external auditor. The article notes that more than 100 of IP's customers had inquired about its certification status

so On the supply side, WWF has also worked to create financing for production of certified timber in poor countries. In 1997 it announced a joint program with the World Bank to assist developing countries to bring 200 million additional hectares under certification by 2005 $<$ http://www.worldbank.org/html/extdr/extme/wwf-wb4.htm>.

s1 E.g., K. Forsyth, Certified Wood Products: The Potential for Price Premiums, in LTSINTERNATIONALREPORT(Scotland 1998); POTENTIAL MARKETS FOR CERTIFIED FOREST PRODUCTS IN EUROPE, EU-project FAIR-CT95-766 Report (Brita Pajari, et al., eds., 1998). 
premium"), to maintain or increase market share, or simply to avoid bad publicity and resultant lower profits. ${ }^{52}$ It seems likely that all three are true in different cases, and sometimes in the same ones.

\section{Environmental Management Systems}

To ensure implementation of its substantive standards, the FSC requires the establishment of an "environmental management system" (EMS) by the forest management organization. ${ }^{53}$ The EMS concept predates the FSC, and is in fact the primary element of the ISO system discussed below. The fundamental idea of an EMS is that the forest enterprise must have organizational arrangements for setting environmental goals, gathering and analyzing information, and planning, monitoring, and revising its plans. Such arrangements can be quite elaborate in large organizations, and could be difficult for small enterprises to implement. Because of the importance of certifying small- and medium-sized firms, the FSC's EMS requirements do not appear particularly demanding. Regional and national standards typically require (1) a document stating management objectives, detailing the forest resources involved and their condition, and describing planning, implementation, and monitoring procedures and (2) some implementation efforts, such as communication of the general framework of the plan to employees. These requirements are often reduced for small firms. ${ }^{54}$

52 See Hannah Scrase, Certification of Forest Products for Small Businesses: Improving Access - Issues and Options, Final Report to United Kingdom Department for International Development (DFID), Renewable Natural Resources Knowledge Strategy (RNRKS), Forestry Research Programme (FRP) pre-project ZF0083, September 8, 1999<http://www.fsc-uk.demon.co.uk/DFIDREP3.rtP (on file with author); see also Pajari, supra note 51.

33 See UPTON \& BASS, supra note 38. See also Synott, supra note 17.

54 See, e.g., the Maritime Regional Standards $\S$ 7.1.5.3 $<$ http://www.web.net/fscca/standard.htm> (requiring landscape level plans for enterprises larger than 500 hectares, but not for smaller ones); Swedish FSC Standard for Forest Certification, Appendix $2<$ http://www.fsc- 


\section{Group Certification}

Because economies of scale make certification more costly per unit of production for small producers than for large ones, ${ }^{55}$ the FSC allows the joint certification of groups of producers. ${ }^{56}$ The certificate is held by the group or by an individual responsible for the group. Wood from complying members' lands is entitled to the full benefits of certification. Groups can take many forms, including preexisting ones formed for other purposes and new ones formed especially for purposes of certification, possibly by an entrepreneurial group manager. The FSC policy provides very general guidelines about the allocation of responsibility between the group entity and its members. The group entity is generally responsible for communicating with the certifying entity and group members, carrying out the administrative requirements of the certification, and implementing group level management and monitoring responsibilities. Members are generally responsible for conforming to the requirements of certification and actually managing the land. ${ }^{57}$ In light of the tremendous potential variability among groups and the low level of experience with group certification, the guidelines leave substantial latitude to certifiers to define appropriate relationships and control measures. ${ }^{58}$ Particular areas of concern include how to fairly sample compliance by group members, what to do about individual

sweden.org/gron/stand.htm> [hereinafter Swedish FSC Standard] (distinction between enterprises with less than 5,000 hectares of productive forest land and those with more); Guidelines for Sustainable Forest Management, German FSC Standards, $2^{\text {nd }}$ Draft $\$ 7.2<$ http://www.fsc-deutschland.de $>$ [hereinafter German FSC Standards] (allowing enterprises of less than 150 hectares to submit management reports based on expert assessment, rather than full scale management plans).

E.g., Scrase, supra note 52, at 8; UPTON \& BASS, supra note 38, at 106; Elliott, Forest Certification, supra note 8, at 24.

56 See Group Certification: FSC Guidelines for Certification Bodies, FSC Doc. 3.6.1 (July 31, 1998) <http://www.fscoax.org/html/groupp.html>. 
members who might not operate at the desired level of quality, and how to assess the capacity for long-term management by a group. ${ }^{59}$ Because group certification has the potential to develop new, nonstate-based, coordinative management mechanisms without consolidating ownership, it deserves close study from both an academic and a policy perspective. ${ }^{60}$

\section{Program Operation}

\section{Certification Patterns}

By the Fall of 1999, approximately 17 million hectares ( 42.5 million acres; 66,000 square miles) of forest had been certified in a total of approximately 190 separate certificates granted by the six approved certification organizations. ${ }^{61}$ Approximately 80 percent of the certified land is located in developed countries, and 20 percent is in developing countries. ${ }^{62}$ Two-thirds of the certified land is managed by industrial enterprises, while less than five percent is held by communities. ${ }^{63}$ The proportion of private to public land varies greatly among regions. ${ }^{64}$

$59 \quad$ See id.

60 See generally, Ronald H. Coase, The Nature of the Firm, 4 ECONOMICA 386-405 (1937) and the literature following it, including William G. Ouchi, Markets, Bureaucracies, and Clans, 25 ADMIN. SCI. Q. 129-41 (1980) and Oliver E. Williamson, Comparative Economic Organization: The Analysis of Discrete Structural Alternatives, 36 ADMIN. SCI. Q. 269-96 (1991).

61 See FSC List of Certified Forests, FSC Doc. 5.3.3 (October 31, 1999) $<$ http://www.fscoax.org/principal.htm>.

62 See Kirsti Thornber, Overview of Global Trends in FSC Certificates (International Institute for Environment and Development ed., 1999) (on file with author).

${ }_{63}$ See id. at 3 . The remainder of the land is held by states (22\%), joint ( $\left.8 \%\right)$, and small private $(1 \%)$ enterprises. See id.

$64 \quad$ See id. 


\section{The Certification Process}

Although it plays a major role in defining and implementing the FSC Principles, and although many millions of hectares of forest have been certified, the certification process remains somewhat shrouded in mystery. We do know a number of things about it, however. A typical certification process takes from one to three weeks' effort by a team of several people. ${ }^{65}$ Certifications may cost anywhere from $\$ 500$ to $\$ 130,000$ US, though the lower figure is unrealistic for any but the simplest situations.$^{66}$ Certifiers commonly perform pre-certification checks to determine whether potential applicants are "in the ball park" for certification, and often suggest what actions would be needed to attain certification. ${ }^{67}$ Some certifiers provide potential applicants with simple checklists so that they can make ball park determinations on their own. ${ }^{68}$ If a certification process is undertaken, it is likely to begin with a scoping visit, in which a project team is put together and a work plan developed. ${ }^{69} \mathrm{~A}$

See Kate Heaton \& Richard Z. Donovan, Forest Assessment, in CERTIFICATION OF FOREST PRODUCTS: ISSUES AND PERSPECTIVES 62 (Virgilio M. Viana, et al. eds., 1996).

66 See UPTON \& BASS, supra note 38 , at 105 . The cost of certifying a community forest management project in Bolivia was estimated at $\$ 47,525$. See Matthew Markopoulos, The Impacts of Certification on Community Forest Enterprises: A Case Study of the Lomerio Community Forest Management Project, Bolivia, Report to the Int'I Inst. for Env't. and Dev., Forest and Land Use Series No. 13, Apr. 1998 [hereinafter Markopoulos, Bolivia]. These numbers do not reflect the potential costs of changing management practices to achieve and maintain certification. There remains a great deal of uncertainty about the actual costs of certification, and this is apparently an additional impediment to wider use of certification. See Scrase, supra note 52.

67 See UPTON\&BASS, supra note 38, at 66. Pre-certification assessments can also evidently be important to forestry firms seeking external financing, and certifiers apparently allow them to be used for that purpose. Id. See also, UK FSC, Certification Step by Step <http://www.fscuk.demon.co.uk/localauthorities.html\#StepbyStep>.

Personal communication.

See UPTON \& BASS, supra note 38 , at 84. 
typical team includes experts in at least forestry, ecology, and social science $^{70}$-- some of them local. ${ }^{71}$ The work plan is likely to involve both a document review and a field assessment. ${ }^{72}$ The field assessment will involve checks of resource management operations and interviews with external stakeholders. ${ }^{73}$ Both aspects require sampling, since it is not possible to examine every hectare or interview every interested party. ${ }^{74} \mathrm{~A}$ field visit takes at least several person days and usually more, depending on the size of the operation.

The field visit typically concludes with a presentation of preliminary findings by certifiers to the applicant and a discussion of their validity. ${ }^{75}$ The results of the certification process are then subjected to a peer review "to attest to the technical credibility of the assessment methodology of a particular certification exercise and to examine the conclusions reached by the assessment team." ${ }^{176}$ Reviewers are chosen by the certification organization, ${ }^{77}$ subject primarily to the criterion of professionalism. Certifiers apply different methods to deciding whether to grant a certificate. Some use numerical systems ${ }^{78}$ others make overall qualitative judgments. ${ }^{79}$ In either case, however, a great deal of discretion is involved, since numbers are simply ways of organizing professional judgments in the first place.

When certifications are granted, they generally specify conditions requiring improvement. ${ }^{80}$ These can take the form of "preconditions," which must be met before the certification becomes

See Heaton \& Donovan, supra note 65, at 62.

See id. See also, Maritime Process, supra note 14.

See Heaton \& Donovan, supra note 65.

See id.

See id.

See id.

UPTON \& BASS, supra note 38, at 97.

See id.

See Heaton \& Donovan, supra note 65 , at 66 .

Personal communication.

See Heaton \& Donovan, supra note 65 , at 66. 
effective, or "corrective actions" specifying improvements that are to be made within a set time after the certification. ${ }^{81}$ Certifiers are expected to monitor compliance, but seem to have considerable discretion in how to do so. ${ }^{82}$

Conceptually, certification is an inherently complex process. It involves checking and assessing potentially hundreds of standards and indicators ${ }^{83}$ over large areas and in highly variable environmental and social conditions. No applicant is expected to fully meet every standard and criterion. Certifiers therefore must make judgments about whether, overall, an operation is "well managed" enough to meet the Principles and Criteria and any local standards. In doing so they must give concrete meaning to the Principles, Criteria, and standards, and then make an overall balance to decide how much compliance is enough. At present, how that is done is very poorly understood outside professional certifier circles.

Our limited understanding of the on-the-ground certification process significantly constricts our understanding of the role of the certification process in sustainable development policy. While there are some good reasons for the opaque character of certification (including confidentially concerns, ${ }^{84}$ the technical complexity of the

81 See Elliott, Forest Certification, supra note 8, at 21.

82 Compared to the AF\&PA Sustainable Forestry Initiative discussed in Section III, the FSC system leaves a large amount of discretion in the hands of the certifier. The AF\&PA gives much more control over these issues to the forest management organization.

83 The Canadian Maritime Regional Standard, for example, contains over 150 individual standards and almost 250 additional indicators. See Maritime Regional Standard, supra note 54. Some standards are somewhat shorter, and contain shorter lists of indicators, but it seems unlikely that certification under them will be significantly simpler.

84 Many forestry firms will understandably be hesitant to risk disclosure of proprietary information on their forest stocks and management practices, and may avoid certification if such disclosures result. 
decision process,${ }^{85}$ the costs of transparency ${ }^{86}$ and the risks of unfair criticism of certification decisions ${ }^{87}$ ), opacity also creates some significant problems. We know from research on other compliance and enforcement processes that a great deal of discretion is present in decisions on particular cases, and that how it is used varies considerably. ${ }^{88}$

Because the exercise of case-level discretion is an important part of any policy process, scholars generally agree that it should be subject to some form of discipline, whether through rules governing its application, ${ }^{89}$ supervisory oversight, ${ }^{90}$ or extensive information disclosure. ${ }^{91}$ The FSC system relies on the professionalism of certifiers and the possibility of FSC oversight to discipline the system. However, these may be weak reeds on which to hang the system's legitimacy. First, certifier professionalism, while valuable and crucial, is exercised in a market context where certifiers need to satisfy current clients and gain new ones. Thus they may feel

85 Policy decisions are intertwined with many gritty factual details and technical issues, and are not easy to disentangle from them.

86 Certifiers argue that it is already quite expensive simply to perform certification reviews, and that subjecting them to additional documentation and research would inappropriately raise the costs to the party seeking certification. Personal communications.

87 The inherent discretion in the decision process combined with the need to balance multiple considerations means that it will often be easy to cast certification decisions in a bad light. Unfair or manipulative criticisms would not seem unlikely, given the competing interests of non-certified firms and other certification systems. 88 E.g., KEITH HAWKINS, ENVIRONMENT AND ENFORCEMENT: THE SOCIAL DEFINITION OF POLLUTION (1984); MICHAEL LIPSKY, STREET-LEVEL BUREAUCRACY : DILEMMAS OF THE INDIVIDUAL IN PUBLIC SERVICES (1980).

89 E.g., KENNETH C. DAVIS, DISCRETIONARY JUSTICE (1969) (asserting that the organization holding the discretion should make rules for its exercise); THEODORE LOWI, THE END OF LIBERALISM (1969) (proposing that the legislature should make clear rules for the exercise of discretion).

9o E.g., Susan Rose-Ackerman, Reforming Public Bureaucracy through Economic Incentives, 2 J. LAW, ECON. \& ORG. 131 (1986).

91 E.g., Eric W. Orts, Reflexive Environmental Law, 89 NW.U.L. REV. 12271312 (1995). 


\section{BUFFALO ENVIRONMENTAL LAW JOURNAL [Vol 7}

complex incentives to "be reasonable" and possibly to develop market niches involving distinct, albeit subtle, reputational differences. ${ }^{92}$ Second, the FSC's administrative resources, as noted above, are quite limited, and it does not appear to have the capacity to conduct extensive certification reviews. ${ }^{93}$ Third, the private control of certification information inhibits the dialogue among certifiers and the public that is likely to be essential both to achieving consistency among certifiers and to developing publicly legitimate definitions of appropriate forest practices. In the future, therefore, it seems likely that an increased level of external review, possibly including systematic academic research, will be necessary to illuminate and legitimate the FSC certification process.

92 Similar problems affect public permitting processes, such as the US Environmental Protection Agency's implementation of the Clean Water Act:

Congress wanted technology-based standards to apply uniformly to similar sources across the nation, but the permits were negotiated on an individualized basis incorporating whichever control measures and compliance schedules dischargers would accept. EPA characterized these permits as grounded on "best professional judgment;" but they often reflected simply the "best deal" the Agency could obtain in light of manpower and time constraints and its desire to demonstrate progress. These "best professional judgments" were usually made by EPA regional personnel with water quality, not technology-based orientations.

Howard Latin, Regulatory Failure, Administrative Incentives, and the New Clean Air Act, 21 ENVTL. L. 1647, 1672 (1991).

93 Again, the EPA's ability to effectively review state permitting decisions, despite its enormity relative to the FSC, has been quite limited. E.g., Victor B. Flatt, A Dirty River Runs Through It (The Failure of Enforcement in the Clean Water Act), 25 B.C. ENVTL. AFF. L. REV. 1 (1997); John P. Dwyer, The Practice of Federalism Under the Clean Air Act, 54 MD. L. REv. 1183 (1995). 


\section{Regional and National Standard Setting}

The FSC system is designed to facilitate place-based public dialogue in the regional and national standard setting processes. These processes are to adapt the Principles and Criteria to regional conditions and to provide concrete guidelines for certifiers. Work on standards is currently underway in a number of standard setting groups; approved standards have been completed by a few. The groups vary considerably in composition and organization. Many, such as the British, ${ }^{94}$ Danish, ${ }^{95}$ German,${ }^{96}$ and Swedish ${ }^{97}$ ones, mimic the tripartite environmental-economic-social structure of the international FSC. Some add another sector or two, such as the Cameroonian effort, which also has government and research sectors. ${ }^{98}$ Some, such as the first British Columbia standard writing process, evidently have narrower bases. ${ }^{99}$ Still others, such as the Canadian Maritime Region, which involved nine categories of interests, are built to reflect more complex local stakeholder structures. ${ }^{100}$ Drafting can be done either by committee members or by consultants. Several of the earlier processes, such as the British and Swedish ones, used consultants to draft standards and then

94 See Status of National and Regional Certification Initiatives, FSC Doc. 4.3.3., at 20 (March 1999) [hereinafter "FSC Status Report"] $<$ http://www.fscoax.org/html/4-3-3.htm>.

$95 \quad$ See id. at 9 .

96 See German FSC Website <http://www.fsc-deutschland.de/fscag.gif>.

97 See FSC Status Report, supra note 94, at 19.

$98 \quad$ See id. at 6.

99 According to Hoberg, the British Columbia regional standard writing committee was composed of a "close-knit group of environmentalists with no involvement from major $\mathrm{BC}$ forest companies." Its draft standards are to be redone by a more broadly based group. See George Hoberg, The Coming Revolution in Regulating our Forests, 20 POLICY OPTIONS 53, 54 (December 1999).

${ }_{100}$ See Maritime Process, supra note 14. The Maritime Process also suffered from very limited participation by industrial forestry interests. See subsection (a) infra. 
committees to review and revise them. ${ }^{101}$ Later ones, such as the Maritime and evidently most of the North American efforts, seem to rely primarily on committee members.

Because it was one of the earliest and best documented standard setting processes, and because it worked with a complex stakeholder structure, the Canadian Maritime process is described below to give a flavor for the regional standard setting process. Other processes are compared to give a sense of variation.

\section{a) The Canadian Maritime Process}

The Canadian Maritime Region, for FSC standard-setting purposes, covers the provinces of New Brunswick, Nova Scotia, and Prince Edward Island. The Canadian FSC purposely sought to build a standard writing committee representing stakeholder groups in the region. The Technical Standards Writing Committee ("Writing Committee"), which did most of the standard development, had eighteen members representing nine self-defined categories: First Nations, large industry, small industry, professionals-academics, environmentalists, community groups, youth, woodlot owners, and government. ${ }^{102}$ The Writing Committee members were selected by people who classified themselves as members of the groups the Committee members were to represent, and who attended a large public meeting to inaugurate the regional standard writing process. The Writing Committee met approximately monthly (sometimes for several days at a time) over the course of two years to develop a draft set of standards and then to redraft them. The effort was supported by small grants from foundations and a great deal of donated time. Provincial forestry authorities were invited to participate in the process but declined to do so. They did, however, make two individuals available to the Writing Committee as "technical advisory support." Most of the standard writing occurred indoors, but the 
Committee did hold a "mock certification" in several woodlots a little over half way through the drafting process, and expressed the view that this was a very good thing that probably should have been done earlier. ${ }^{103}$

The Writing Committee's meetings were closed to the public, and its deliberations were subject to a confidentiality agreement. ${ }^{104}$ Although the Committee established rules for voting, it never actually voted. Instead, it sought to achieve consensus, often through extended meetings and dialogues. ${ }^{105}$

We decided early on that issues would be discussed until all views were on the table, and then, if consensus seemed highly unlikely, we would move on to another point. In this way we worked through all the common ground, and we found we had much more in common than we thought. At each meeting we returned to the difficult points and, miraculously, they began to disappear. By the end of March, 1998, two years after beginning the process, there were only three points on which we could not reach consensus: biocide use, introduction of exotic tree species, and the amount of protected area that was required to be set aside by large industrial owner/managers. ${ }^{106}$

See id.

See id.

105 See id.

106 Id. This document is presented as the collective memory of the group. Authorship is not attributed. 
A sense of how the areas of disagreement were worked out can be gleaned from the progress of the biocide rule. The spring 1998 draft was structured as follows:

6.6 Management systems shall promote the development and adoption of environmentally friendly non-chemical methods of pest management and strive to avoid the use of chemical pesticides. World Health Organization Type A and B and chlorinated hydrocarbon pesticides; pesticides that are persistent, toxic or whose derivatives remain biologically active and accumulate in the food chain beyond their intended use; as well as any pesticides banned by international agreement, shall be prohibited. If chemicals are used, proper equipment and training shall be provided to minimize health and environmental risks.

6.6.1 An owner/manager must adopt management systems that are designed with the intention of eliminating dependence on and use of biocides.

6.6.2 The use of biocides or synthetic chemical fertilizers must be considered negative from an ecological perspective.

6.6.3 (Track 1) The use of biocides or synthetic chemical fertilizers is prohibited, except in circumstances where there is a clear scientific justification based upon ecological risk/benefit analysis for each specific situation.

6.6.3 (Track 2) The use of biocides and synthetic chemical fertilizers is prohibited, except in rare circumstances in which it can be shown that the use of these substances will benefit ecosystem health.

6.6.3 (Track 3) Use of biocides or synthetic chemical fertilizers is prohibited. 
The version adopted reads as follows:

\begin{abstract}
6.6.1 * The use of biocides and synthetic chemical fertilizers are [sic] prohibited, except in the very rare cases where an exotic invader threatens the existence of indigenous plant or animal populations and when there is no alternative method available. ${ }^{107}$
\end{abstract}

Similar compromises, quite environmentally protective on the whole, were made in resolving controversies over exotic species and bio-diversity protection on large private landholdings. The traditionally divisive issue of clear-cutting ("even-aged management") was resolved by reference to the overall goal of restoring what was understood to the natural forest of the region. Since that forest contained large amounts of fire dependent species such as jack pine, clear cutting is allowed when it serves as a surrogate for fire. Clear-cut opening sizes are limited to 5 hectares and must have irregular perimeters. Clumps of live trees and abundant standing and downed coarse woody debris must also be left on site. How the biocides and clear-cutting rules will fare with the timber industry is uncertain at best. Heavy industry complained frequently about being under-represented in the process, and seems often to have chosen not to participate even when it could have. ${ }^{108}$

107 Id. The single asterisk $\left(^{*}\right)$ after the section number indicates that failure to meet this standard would be a "major problem" for certification. "If the applicant for certification fails at this level, conditions must require remediation within a reasonable time in order for the applicant to maintain certified status. Two asterisks would indicate a 'fatal flaw.' If the applicant for certification fails at this level, the audit report must contain 'preconditions' requiring remediation which will result in a passing mark before certification can be granted." Id.

${ }_{108}$ It is also interesting to note that at least one certifier employed as a consultant to the process counseled the writing committee against setting such strict criteria for clear-cutting and biocide use. He suggested leaving the issues to 
The Writing Committee's official history suggests that members experienced a certain amount of deliberative learning ${ }^{109}$ in the process:

It is interesting that individuals from interest groups directly represented (in some cases from the same organization) on the committee sometimes disagreed with things that received approval from their colleagues. This is a strong indication of the power of this sort of wide-open consensus process. Those that participated actually evolved in their understanding through the process, whereas those from the same groups, or organizations who did not participate maintained their original viewpoints. ${ }^{110}$

Those "disagreeing outsiders" may have their say over time, since the regional FSC envisions a dynamic process of continuous feedback with revisions in the standard to occur every two years, and since the Maritime Region FSC Standards are still subject to an internal challenge. ${ }^{\prime \prime \prime}$

\footnotetext{
"certifier discretion." Id.

109 See generally Ortwin Renn \& Katharina Zoeller, The Challenge of Interpreting Deliberation and Expertise: A Model Procedure for Integrating Knowledge and Values (paper presented to the American Association for the Advancement of Science, 1998) (on file with the author).

110 See Maritime Process, supra note 14. "Sometimes we came to agree that the best solution on a particular point was not the one favoured by all the organizations we represented; this caused some of us grief "at home" where our friends/colleagues/bosses did not have the benefit of soaking in all the views around the table." Id, entry for June 25, 1998.

III Personal communication. There is also some evidence that the Canadian Forest Industry may have decided to become much more involved in regional standard setting processes. See Hoberg, supra note 99.
} 
After the Writing Committee had completed a second, nearfinal draft in the spring of 1998, a Regional Steering Committee ("Steering Committee") to guide the next phases of the effort was selected by acclamation at a large public meeting. The nineteen members were organized in four "houses" -- First Nations, Economic, Environmental, and Social, but were sometimes also listed as a more diversified group similar to the Writing Committee. Indeed some of the Steering Committee members had also been Writing Committee members. The Steering Committee contained more landowners actually involved in forestry - mostly small "woodlot owners." 112

After the second draft had become the third and semi-final draft, the Steering Committee sought to "harmonize" it with draft standards in other regions and countries with comparable forests. A consultant prepared a harmonization report, ${ }^{113}$ and the Steering Committee then decided whether and how to conform the Maritime standard to standards from other regions. After the harmonization process, the standard went to FSC International for possible approval. The standard was reviewed and returned to the Steering Committee with the indication that it would be approved after the Steering Committee responded to comments regarding the conversion of hardwoods to pine forests, low value-added, and biocide use. ${ }^{114}$ It was eventually approved, but after intense discussions about improving the "balance" of the standard writing group and the substance of the biocide provision in particular. ${ }^{115}$ As of this writing a new regional

112 See Maritime Process, supra note 14.

11 Karen Tam, Comparison of Maritime Region Draft Standards with Great Lakes-St.Lawrence Region Draft Standards and North-East Region (U.S.) Draft Standards, Appendix C -- Harmonization Reports (July 1998) $<$ http://www.canadian-forests.com/fsc-process.html $>$.

114 Regional and headquarters FSC officers had not responded to queries about the content of those comments as this article went to press.

IIs See Olaf Johansson, FSC Board of Directors Chair \& Timothy Synott, FSC Executive Director, Statement on the FSC Endorsement of the Maritime Regional Standards, <http://wwws.fscus.org/news/maritime_statement.html>. 
committee is being constituted, presumably with greater representation of industrial forest interests. The biocide provision is expected to be reworked "interpreting the FSC Principles and Criteria in a broader sense."116

The general contours of the Maritime standard writing process resemble what American administrative lawyers would call a negotiated rulemaking process (a "reg-neg"), ${ }^{117}$ with two important exceptions. First, the stakeholder participants have greater control over the content of the standard than would a reg-neg group. While FSC International reviews standards and requires changes prior to adoption, it does not have the option of writing an entirely different site-specific standard as would an agency in the reg-neg process. ${ }^{118}$ Second, the meetings of the Maritime standard writing group were closed, whereas reg-neg meetings must be publicly announced and open under the Federal Advisory Committee Act. ${ }^{119}$ The decision to keep the Maritime standard writing meetings closed was controversial. The group acknowledged that the policy was in tension with the ideal of transparency, but largely defended it as necessary to making progress in a politically charged environment. ${ }^{120}$

\section{b) General Issues}

The role of stakeholders in standard development is likely to remain a point of contention. There are two dimensions to the question. The most obvious problem is which stakeholders should be directly represented in the standard writing process. As suggested above, the environmental/social/economic framework is vaguely suggestive, but provides no clear guidance. The biggest question for

$116 I d$ I

117 See Negotiated Rulemaking Act, 5 U.S.C. \$\$561-570a; see generally, Jody Freeman, Collaborative Governance in the Administrative State, 45 UCLA L. Rev. 1 (1997).

118 See USA Group Loan Services, Inc. v. Riley, 82 F.3d 708 (7th Cir. 1996)

119 Federal Advisory Committee Act, 5 U.S.C. Appx prec $\S \S 1-15$.

120 See Maritime Process, supra note 14. 
a program with origins in the environmental movement is how much industry involvement is appropriate. In the early going there seems to have been a relatively low level of industry involvement in many standard setting processes, particularly in North America. In many cases, this may have been by mutual consent. As this article goes to press, however, there seems to be a rethinking on both sides, with both the FSC and industry seeking greater industry involvement. ${ }^{121}$

A second problem is how standard writing bodies should relate to stakeholders who have been defined as external. A number of FSC standard setting bodies have experienced conflicts regarding the appropriate role of national and international environmental and other interest groups. Some participants, perhaps more influenced by professional foresters and technical experts, have sought to confine standard setting processes to knowledgeable regional stakeholders working around a table together. Others, perhaps more influenced by traditional environmental activists, have sought to bring transregional constituencies to bear on regional standard setting processes through the use of direct lobbying, letter writing campaigns, threats of negative publicity, and the like. ${ }^{122}$

A widely cited difficulty is how "high" to set standards. One interviewee describes the issue clearly:

The problem that we're coming up against is that the [regional standard setting] groups are setting the bar for developing standards at different heights. ... In some cases the groups are setting the bar so that they "certify the best," which is, you know, setting the bar pretty high. And in other cases the groups are setting the bar at a lower level so they can "certify the rest," bring them on board, and then incrementally step up the bar as they have buy-ins from landowners. ${ }^{123}$

See Hoberg, supra note 99; personal communications. 
The primary FSC solution to this problem is the "harmonization" process described above. This is an important process, but it will frequently require preferring one regional standard setting group over another. It thus faces the possibility of creating significant discontent among participants in processes whose standards will need to be modified. ${ }^{124}$ The problem is exacerbated by the possibility of certifying public land, which some people from both industry and environmental groups argue should be held to a higher standard than private land. ${ }^{125}$

\section{Implications for Environment, Community, and Human Rights}

The implications of the FSC certification system for environment, human rights, and community remain an open question, since experience with the system is brief. Some tentative conclusions can be suggested, however.

As one participant put it:

FSC is looking into ... how they can harmonize ... without

giving the impression that this is a top down approach coming out of FSC. So it's a real kind of a juggling act that's going on right now between the regions and the national headquarters.

Personal communication.

125 The Sierra Club recently raised the stakes by taking the position that there should be "zero cut" from the federal lands, including those managed by the Forest Service and the Bureau of Land Management. See Sierra Club Website, $<\mathrm{http}: / / \mathrm{www}$.sierraclub.org/forests/ $>$. Other environmentalists fear that, in addition to precluding any form of traditional certification, this has the potential to split the environmental movement between those who back the zero cut option and those who would be happy with greatly improved practices on federal lands, even if they involve some logging. Personal communications.

No federal lands have received FSC certification to date, and the Forest Service is on record with the position that it does not intend to seek third party certification for any of its lands. See Memorandum from Acting Deputy Chief Janice McDougle (May 8, 1997). See also FSC U.S. Website, $<$ http://www.fscus.org/current_issues/federallands.html>. 


\section{Environment}

The Maritime region's primary focus on traditional "environmental" issues -- biocides, clear cutting, exotic species, and biodiversity protection -- also seems to characterize the FSC system generally. The Principles and Criteria, and the standards they have spawned, are highly environmentally protective on the whole. Were they to be universally applied, the condition of the world's forests would improve greatly. The standards are voluntary, however, and their actual effects are contingent on how widely they are adopted and followed. At this time, the amount of FSC certified forest, while substantial in its own right, is miniscule relative to the world forest environment -- approximately 0.5 percent. ${ }^{126}$

Most of the enterprises that have sought or received certification to date appear to have started with relatively high management standards. Thus the marginal environmental improvement resulting from certification on those lands has not been great. ${ }^{127}$ On the other hand, it is possible that certified products will command higher prices than non-certified products over time, or that certification will become increasingly necessary to retain market share (although knowledgeable observers disagree about both prognostications). ${ }^{128}$ To the degree that either or both of these conditions apply, some substandard producers may be prompted to raise their management standards to obtain higher prices or retain market share. Nonetheless, the certified market in the near to medium terms seems likely to remain small. For example, one analyst puts it at no more than $25 \%$ of the European market by 2005 , and

126 This calculation assumes a total global forest area 3,454 million hectares, as reported in Rachel Crossley \& Jonathan Points, Investing in Tomorrow's Forests, Report to the World-Wide Fund for Nature, 1998, at 27 $<$ http://www.panda.org/forests4life/ffl pub.htm>. Their figure is derived from FOOD AND AGRICULTURE ORGANIZATION OF THE UNITED NATIONS, STATE OF THE WORLD'S FORESTS (1997).

${ }_{127} \quad$ See Thornber, Equity and Certification, supra note 18.

128 See supra discussion accompanying notes 42-52. 
significantly less elsewhere. ${ }^{129}$ Certification also has no impact on practices such as "timber mining" and conversion of timberland to other uses (such as ranching), which pose the greatest immediate threats to forest ecosystems. ${ }^{130}$ Finally, the FSC system also has difficulty dealing with landscape level problems. Since it certifies individual producers in more or less the same way that a regulatory agency handles individual "cases," coordinating management among different producers, which perhaps should pursue different goals to maximize overall environmental conditions, will be difficult. The primary hope here is that the FSC certification system will create sufficient cross-ownership dialogue to promote increased joint goal setting and coordination. ${ }^{131}$ However, the degree to which this will actually occur is highly speculative at present and will require considerable future research to ascertain.

In sum, the environmental effects of the FSC as a free standing voluntary system are likely to be positive but modest. Two additional types of dynamics, however, have the capacity to amplify the effects of the FSC program. The first is incorporation into traditional legal systems. Although this could occur through the formal adoption of FSC standards or requirements by either legislatures or administrative agencies, not many legal systems seem likely to take this route in the near term. However, incorporation can also occur through the informal, often almost invisible adoption of FSC requirements into existing legal regimes. These include the definition of best management practices in administrative regulation,

129 See Ewald Rametsteiner, Policy Analysis of Certification of Forest Management as a Policy Instrument to Promote Multifunctional Sustainable Forest Management 6, Report to the European Forest Institute, May 1999.

130 This is not to assume that all conversions are undesirable. There are undoubtedly some conversions to farm land that most observers would find acceptable and perhaps desirable. See Thornber, Equity and Certification, supra note 18 , at 6.

131 See, e.g., Elliott, Forest Certification, supra note 8, at 458; Errol Meidinger, Laws and Institutions in Cross-Boundary Stewardship, in Richard L. Knight \& Peter B. Landres, STEWARDSHIP ACROSS BOUNDARIES (1998). 
tort law, financial reporting, and so on. Although the process of informal incorporation cannot be analyzed or described in any detail in this article, it does seem likely to move forward in the near term, thereby expanding the effects of the FSC program beyond what is apparent in its own terms. ${ }^{132}$

A second potential means of amplification is through the operation of other non-governmental forestry programs. It seems clear that some other forest certification programs have been spurred into existence by the FSC initiative. Although they may have been partially intended to fend off what were seen as overly stringent standards, the other programs are still caught in a dynamic that pressures them to make their systems credible, and that dynamic has led to more serious standards and verification systems over time. ${ }^{133}$ Thus it seems likely that the FSC program will lead to improvements in environmental management beyond the domain of firms actually certified in the FSC system. The magnitude and durability of those changes, of course, remains to be seen, and it is possible that the proliferation of programs will ultimately undermine the possibility of a single strong one emerging.

\section{Human Rights}

Most human rights issues fall under the rubric of social concerns in the FSC system. The FSC's effort to advance social concerns in both its organizational structure and its Principles reflects its origins in a world-wide dialogue on "sustainable development," a dialogue which pursues the mutual accommodation and integration

132 For an analysis of this process in the North American context, see Errol Meidinger, Incorporating Environmental Certification Systems in Traditional Legal Systems: the American Case (paper prepared for the Conference on The Integration of Voluntary Approaches into Existing Legal Systems, Brussels, Feb. $24-25,2000)<$ <ttp://www.ublaw.buffalo.edu/fas/meidinger/certlaw.pdf [hereinafter Meidinger, Incorporating Certification Systems].

${ }_{133}$ See the discussion of the changes in the AF\&PA program in Section IV. 
of economic, environmental, and equity (social) goals. ${ }^{134}$ Many FSC social concerns include both human rights and community issues. These issues are often intertwined, of course, and are somewhat arbitrarily divided between this section and the next. The FSC program is also related to a long line of voluntary codes and certification programs seeking to promote human rights, which cannot be canvassed in this article. ${ }^{135} \mathrm{FSC}$ human rights concerns are of two general types: (1) natural resource control and access and (2) worker safety and employment.

\section{a) Natural Resource Control}

FSC Principles 2 and 3 are emphatic in protecting long term tenure and use rights, as well as legal and customary rights of indigenous peoples: ${ }^{136}$

2. Long-term tenure and use rights to the land and forest resources shall be clearly defined, documented and legally established.

3. The legal and customary rights of indigenous

134 See infra note 29. For a comprehensive discussion, see Elliot, Forest Certification, supra note 8, at 94-155.

135 See generally Janelle Diller, A Social Conscience in the Global Marketplace? Labour Dimensions of Codes of Conduct, Social Labelling and Investor Initiatives, 138 INT. LAB. REV. 99-129 (1999) (surveying 215 voluntary codes and 12 social labeling programs); Douglass Cassel, Corporate Initiatives: $A$ Second Human Rights Revolution? 19 FORDHAM INT'L L.J. 1963-84 (1996); Robert J.Liubicic, Corporate Codes of Conduct and Product Labeling Schemes: the Limits and Possibilities of Promoting International Labor Rights Through Private Initiatives, 30 L. \& POL. IN INT'L. BUS. 111-58 (1998).

136 Seesupratext accompanying notes 28-31. These provisions are consistent with a series of international legal instruments that have been drafted and adopted in recent years to protect indigenous peoples and their relationships to land. For a current survey, see Siegfried Wiessner, Indigenous Peoples, YRBK. INT'L ENVTL. L. (forthcoming 1999) (on file with author). 
peoples to own, use and manage their lands, territories, and resources shall be recognized and respected. ${ }^{137}$

Most national and regional standards are similarly protective. ${ }^{138}$

Principle 2 sounds fairly noncontroversial, but can confront significant difficulties in practice. The main problem is that long-term tenure and use rights are subject to significant doubt in many forested areas. In the Brazilian Amazon, for example, long-term ownership rights are often granted to individual land holders, but are conditional on the land being put to beneficial use. Some scholars have argued that the beneficial use requirement in fact encourages deforestation, both by giving squatters an ostensible justification for clearing land whose title is held by others, and by thus encouraging title holders to preemptively clear land to demonstrate beneficial use. ${ }^{139}$ While the accuracy of this analysis is subject to vigorous dispute, ${ }^{140}$ it illustrates the tensions that can arise between property rights protection and equity concerns.

A second problem occurs when the property rights of the forest management entity are of relatively short duration, perhaps in renewable terms, as is the case with many community forestry operations in developing countries. In these cases the capacity of the forestry operation to promise long-term sustainable management can be in serious doubt, since their ability to manage the resources could disappear entirely with a change in political administrations or other conditions.

137 FSC Principles and Criteria, supra note. 6.

138 See, e.g., Maritime Regional Standards, supra note 54, §§ 2.2 \& 3.2.

139 See Lee J. Alston et al., Land Reform Policies, the Sources of Violent Conflict, and Implications for Deforestation in the Brazilian Amazon, J. ENV'T ECON. \& MGMT. (forthcoming) (on file with author).

140 E.g., Emilio F. Moran, The Law, Politics, and Economics of Amazonian Deforestation, 1 INDEP. J. GLOBAL LEGAL STUD. 397 (1994). 
Principle 3, protecting legal and customary rights of indigenous peoples, also faces both practical and conceptual problems. At the conceptual level, Principle 3 is in considerable tension both with itself and with Principle 2 in many parts of the world. This is because many state legal systems have been used to officially dispossess indigenous peoples from their traditional lands and customs. Thus "legal" title can be in serious tension with customary rights. The doors to recognizing customary rights in state legal systems are not all closed. Indeed, subjected to strong arguments and continuous pressures, some state legal systems have shown a remarkable willingness to reconsider traditional land claims that most citizens probably assumed had been extinguished. ${ }^{141}$ Nonetheless, state land claims adjudications tend to be astonishingly slow, often operating in terms of decades and even half-centuries, and quite expensive $e^{142}$-- not the kind of thing that can be casually included in the course of a certification process.

Moreover, Principle 3's coverage is subject to some ambiguity. What is the reach of the term "their ... resources?" Does the term cover plants that indigenous people traditionally harvested, but that are located on land now belonging to someone else? One could argue either way based on the Principle, and it seems likely that its practical reach will be defined in regional standard setting and in certification processes. ${ }^{143}$

At the practical level, it is not clear how aware certifiers will be of customary claims, given that they are often unrecorded and that landowners may have little incentive to raise them. Even when certifiers are aware of claims, they may find it very difficult to make

\footnotetext{
141 E.g., Oneida Indian Nation v. County of Oneida, 414 U.S. 661 (1974).

$142 \quad I d$.

143 There is also a significant problem with subsurface resources, which in many countries are retained by the government, no matter who owns the surface. The right to exploit these can effectively destroy the forest based rights of indigenous peoples. See S. James Anaya, Environmentalism, Human Rights and Indigenous Peoples: A Tale of Converging and Diverging Interests, infra p. 1 this volume.
} 
determinations on their existence and scope. The Canadian Maritime $^{144}$ and German ${ }^{145}$ standards deal with this possibility by mandating "appropriate" dispute settlement mechanisms, but without defining what they might be. The Swedish standard is more specific. It refers to a government-defined reindeer husbandry area for the Sami people, and it mandates both that legal requirements for reindeer husbandry be met, and that forest managers plan their operations to preserve access to arboreal lichens and areas of special importance to reindeer. ${ }^{146}$

In addressing disputed customary claims, FSC dispute settlement processes will have to decide how to relate to existing governmental processes for defining property and use rights. The FSC processes could either operate independently or invoke governmental decision mechanisms. It may be attractive to certifiers to use governmental mechanisms since they have established procedures and may offer more finality and legal defensibility to decisions. When certifiers create separate dispute resolution processes, however, it is possible that they might play a role in establishing more expansive definitions of customary and indigenous rights than formal legal systems would. ${ }^{147}$ It will be important to observe whether any such expansion occurs.

\section{b) Worker Safety and Employment}

Principle 4 provides that "[f]orest management operations shall maintain or enhance the long-term social and economic well-

144 Maritime Regional Standards, supra note 54, $\S \S 2.3 \&$ 3.1.2.

145 German FSC Standards, supra note 54. The German document also notes that under UN definitions there are no indigenous peoples in the country. See id. ${ }^{146}$ See Swedish FSC Standard, supra note 54, § 4.2.

147 For an explanation of the potential importance of such rights, see Adriana Fabra, Indigenous Peoples, Environmental Degradations, and Human Rights: a Case Study, in HUMAN RIGHTS APPROACHES TO ENVIRONMENTAL PROTECTION (Alan E. Boyle \& Michael R. Anderson eds., 1996). 
being of forest workers. ..."148 Worker well-being is a major focus of standards in a number of developed countries. The Swedish standard says: "The enterprise is responsible for ensuring that the employees have a good working environment, and for the prevention of physical, mental and social ill-health." ${ }^{\text {149 }}$ It also provides:

In choosing work methods and work organization, and in the procurement of equipment, the best overall solution shall be selected, with due weight being given to working environmental, outdoor environmental and economic considerations. The outdoor environment shall not be given priority at the expense of the working environment. ${ }^{150}$

Worker participation in drafting the standard is unmistakable. The underlying discussion noted that workers operating large harvesting machines are likely to be much safer than those walking around in the woods with chain saws, and that the resultant compaction of forest soil may therefore be acceptable. ${ }^{151}$

The German draft standard is not quite as aggressive as the Swedish one in making firms responsible for worker health, but it does require that forest work be "organized and carried out in a way that guarantees comprehensive health and safety protection" and that "safety regulations are observed."152 Forest managers must ensure the rights of workers to join unions, keep employees informed about enterprise developments, and allow workers to actively participate in

FSC Principles and Criteria, supra note 6.

Id.

151 Personal communication.

152 German FSC Standards, supra note 54, § 4.2. 
processes which affect them. ${ }^{153}$ Firms are also mandated to employ workers throughout the year, if possible, and to provide continual education courses for workers. ${ }^{154}$ The practical meaning of "if possible" remains to be worked out, and it will be interesting to see if any changes in employment or operational policies result.

It is hard to know how much health and safety protection certification might bring to workers in developing countries. Many governments and spokesmen of developing countries have resisted such standards on grounds that they would eliminate one of their key economic advantages in world trade -- low labor costs. ${ }^{155}$ Even if FSC certification becomes more widespread in developing countries, prevailing economic conditions make worker protections as strong as those in developed countries highly unlikely. A more likely policy will be the protection of fundamental rights as currently defined by the International Labor Organization:

a) freedom of association and the effective recognition of the right to collective bargaining;

b) elimination of all forms of forced or compulsory labor;

c) effective abolition of child labor; and

d) elimination of discrimination in respect of employment and occupation $^{156}$

\section{$153 \quad$ See id. $\S 4.3$.}

$154 \quad$ See id. $\S \S 4.5 \& 4.6$.

iss See, e.g., Third World Intellectuals' and NGOs' Statement Against Linkages, <http://www.columbia.edu/ jb38/twin-sal12.pdf> (arguing that environmentalists tend to be well meaning but wrong in advocating the linkage of worker rights and international trade, while some of their labor allies are simply interested in preserving preferential market access for themselves).

156 ILO Declaration on Fundamental Principles and Rights at Work $<$ http://www.ilo.org/public/english/10ilc/ilc86/com-dtxt.htm>. In 1999 the FSC general assembly voted to pro-actively include workers and trade unions in the FSC and to build core ILO conventions into certification assessments. See FSC Draft Minutes, supra note 14. 
If so, this will be progress in at least some cases. Two commentators writing several years ago suggest a similar accommodation under the Principles and Criteria:

Experience in the marketplace indicates that consumers are concerned about social issues, such as the rights of indigenous peoples or how a company treats its employees. In most cases it appears the public understands that assessment of social conditions must first be considered within the regional and cultural context, not the international context. Current FSC policies require that certification should assure that there are no obvious abuses and that basic human rights are respected (indigenous land claims, worker safety, and payment at or above the regional minimum wages.) $)^{157}$

In sum, FSC certification can be a positive force for human rights in both developed and developing countries, but its actual effects are unknown at present and are likely to vary considerably by region.

\section{Community}

While community protection can be seen as part of the larger human rights agenda, it is treated separately in this article for two reasons. First, it is important to recognize that environmental management affects the interests and dynamics of place-based groups, and not only of individuals. Second, although indigenous communities are at long last starting to receive some protection under human rights instruments, progress for other place-dependent communities has been much slower. 
FSC Principle 4 mandates that forest management operations maintain or enhance the long-term social and economic well-being of local communities. This may be the vaguest of the FSC requirements, since neither "social and economic well-being" nor "community" is defined, and since it is far from obvious how much an enterprise must or even can do to maintain or enhance them. There is, however, something of an underlying vision to the principle. The idea is that the community, and all its members, be in a productive and harmonious relationship with the forest. The relationship is implicitly reciprocal: the community takes care of the forest and the forest takes care of the community. The promotion of certification can be seen as an external movement to use global market forces to promote this vision of the community-forest relationship. ${ }^{158}$ Even so, how such a relationship is actually defined will depend heavily on local institutions and culture. At one extreme, a community could make all of the decisions about managing the forest and control the flow of benefits from it. At the other, it could rely on others to make decisions that would provide it with an acceptable flow of benefits. Where along the continuum a particular forest falls depends heavily on ownership laws.

\section{a) Community Control}

The full control model applies primarily in forests owned by communities. ${ }^{159}$ Most community owned forests in developed

See Dominque Irvine, Certification and Community Forestry: Current Trends, Challenges, and Potential (backround paper prepared for the World Bank/WWF Alliance Workshop on Independent Certification, Washington, D.C., Nov. 9-10, 1999) (on file with author). One certification organization is a promoter of community forestry certification. Smartwood has virtually specialized in community forestry. It has established local organizational partners in twelve countries to help increase local expertise on and access to certification. See id at 6 . 159 Community forests here are distinguished from state or nationally owned forests. Whereas place-based communities have primary decision making authority with regard to community forests, they are generally only one constituency among 
countries seem to operate with relatively clear rights and governance structures, which often have been worked out over long periods of time. ${ }^{160}$ Thus, although communities may have to operate within an overarching state or federal legal framework, their right to control the overall management of the forest is rarely subject to doubt. Often the difficulty is that forest policies have also become traditional, and therefore difficult to change. In general, however, the closer the daily life of a community is to the management of its forest, the easier it is to mobilize for policy decisions regarding the forest. ${ }^{161}$ Whether a community decides to change its forest management policy or not is a separate question from that of whether it may do so if it wishes.

In developing countries there has been a broad effort to expand the practice of community forestry. This is in response to many unsatisfactory experiences of communities with industrial forestry operations, which can provide very low economic returns to the community while destroying its ability to obtain a reliable supply

many seeking to influence the management of state and national forests, which are typically managed by large bureaucracies under centrally generated mandates.

${ }_{160}$ Such governance structures can be quite complex. In Germany, for example, community forests are often managed for communities by the state forestry administration, and must conform to federal and state laws as well as to community mandates. See Ulrich Schraml \& Klaus Böswald, A National Forest Programme for Germany? Planning and Implementation of Forest-Related Activities in a Highly Industrialized and Densely Populated Country, in PETER GLÖCK ET AL., FORMULATION AND IMPLEMENTATION OF NATIONAL FOREST PROGRAMMES, VOLUME II:STATEOF THEARTINEUROPE 107 (1999). In one recent case of a large-scale group certification of many community-owned forests in the state of Rheinland Pfalz, the communities had to exert considerable pressure in order to prevail upon the state administration to undertake FSC certification. The forest administration agency apparently sees certification as an implicit criticism of its management practices and resents the incursion on its prerogatives by environmentalists. Personal communications.

161 The concept of "daily life" here includes forest product-based work and general recreation. Both types of relationships have supported efforts to seek certification. 
of plants, animals, and fresh water from the forest. ${ }^{162}$ Certification of community managed forests offers a potential way to both increase the community's control over its forest and give it access to global markets. ${ }^{163}$ The challenges can be quite complex, however. This is sometimes because property rights and governance structures are less definite, and communities are uncertain of their capacity to actually control the management of forests over substantial time periods. ${ }^{164}$ But challenges can also derive from latent problems in the definition of "community" and its relation to economic enterprise. In Mexico, for example, approximately 80 percent of forested land is held by about 8000 different communities, most of which are indigenous. ${ }^{165}$ These communities vary enormously in structure and management capacity. ${ }^{166}$ This means at the outset that certifiers will often find it difficult to understand local communities, and to discern what practices will legitimately contribute to their "well-being."

Moreover, community governance structures may not be consistent with good forest management, as understood by certifiers, the FSC system, or the international forestry community. In Oaxaca,

See Deutsche Gesellschaft fur Technische Zusammenarbeit(GTZ), Forest Certification Project, Newsletter, No. 4, Nov. 1999, at 2 [hereinafter GTZ, Newsletter] (on file with author).

${ }_{163}$ As of late 1999, twenty-three community forests had received FSC certification. Most of them were in "natural" forests, in other words forests that had not previously been used for industrial production. The majority also involved certification of multi-community forests. Most of the communities involved agriculturists who had no experience with industrial production of timber, much less producing it for the international market. Although the great majority involved management by community organization, in one case a community gave a concession to a company to manage community forest land under community guidelines. See Irvine, supra note 158, at 2-4.

164 See id.

165 See Matthew D. Markopoulos, Community Forest Enterprise and Certification in Mexico: A Review of Experience with Special Reference to the Union of Zapotec and Chianantec Forestry Communities (UZACHI), Oaxaca, Report to the International Institute for Environment and Development, September 1999 , at 1 .

${ }_{166}$ See id. at 21. 
for example, community forests are generally managed on the cargo system, which involves the rotation of management positions every one to three years, depending on the location. ${ }^{167}$ The system is intended to limit corruption and inequality, and also to increase training opportunities for community members. Unfortunately, it makes continuity in management policy difficult, since new managers might not understand the policies of their predecessors, and may change them in any event. ${ }^{168}$ Problems can be compounded by the fact that all community members are eligible to vote for managers, regardless of their understanding of forestry issues, creating a real possibility that people not well suited to the jobs are elected. ${ }^{169}$

Some Mexican communities are considering responding to management inefficiencies by changing their procedures, for example, by using "handing over" periods between rotations and imposing qualification requirements for certain positions. ${ }^{170}$ Certifiers have occasionally requested such changes as conditions of certification. ${ }^{171}$ Many other traditional communities with informal governance structures also find it difficult to meet the management system criteria of certification. ${ }^{172}$ Directly and indirectly, therefore, certification can imply changing community governance structures that have purposes other than effective forest management. And evaluating whether this is a good thing is neither a straightforward matter, nor necessarily something that can be done by certifiers.

At this stage it is hard to know how much change in communities might occur as a result of certification. It is fair to wonder, however, whether the FSC's concept of community and its relationship to forest management is sufficiently sophisticated to deal with the complexity of traditional real-world communities and their

See id at 45.

See id.

See id.

See id.

See id at v.

See Scrase, supra note 52. 
relationship to the management of complex enterprises in the global marketplace. As one knowledgeable observer with developingcountry experience commented: "One has to be very careful of one's expectations. Otherwise one ends up saying, 'you're a community and you're expected to become an international business.'"173

\section{b) Community Participation}

The FSC certification program provides two general avenues for community participation. The first is in the standard setting process, where the existence of the social chamber and recent efforts to expand its effectiveness have given community members new voices in policy making. ${ }^{174}$ The second is in the certification process, where communities that do not own forests are supposed to have input in forest policy through community participation processes. The Maritime standard, for example, requires that management consider social impacts, and that "[a]s appropriate to the size of the ownership and the circumstances of the local community, local communities and community organizations directly affected by forestry activities must be given an opportunity to participate in the setting of forest management goals and in forest management planning."175 Its compliance indicators, however, require only that the enterprise publicize its operational activities and consider community feedback. ${ }^{176}$ Similarly, the German standard provides that "[t]he local population has the opportunity to get informed about and to comment on management processes which affect them directly."177

Certifiers have attempted to impose similar and possibly stronger requirements in developing countries. In northern Honduras,

\footnotetext{
173 Personal communication.

174 See Irvine, supra note 158 , at 6.

$175 \quad$ Maritime Standards, supra note 54, §4.4.2.

176 See id.

17 German FSC Standards, supra note 54, §4.9. Use of the term "population" conveniently avoids the problem of defining the relevant community.
} 
for example, where small groups of campesinos manage areas of publicly owned forest under usufructuary agreements, the certifier required community participation in forest management. However, that effort confronted a two-fold problem. ${ }^{178}$ First, the campesino groups were struggling to meet the technical and operational demands of the international market and had little capacity to manage more complicated decision making. Second, the local population was highly fragmented and geographically mobile, and had little capacity for meaningful community deliberation. Indeed, it was arguable from a sociological perspective to what degree place-based communities existed. ${ }^{179}$ In Markopoulos' analysis, imposed participation

178 See Matthew D. Markopoulos, The Impacts of Certification on Campesion Forestry Groups in Northern Honduras, Report to the Int'l Inst. for Env't. and Dev., Jan. 1999, at 44 [hereinafter Markopoulos, Honduras].

179 See id. at 45. Markopoulos' analysis deserves quotation:

Community forest management is a fashionable concept. Like all community-based approaches to sustainable development, however, it is based on a number of assumptions about community, environment and the relationship between them... . The fundamental assumptions are that a distinct, homogeneous community actually exists, and that it is capable of collective action towards common economic and environmental goals. In the campesino communities of the Atlantida region, there is little justification for either of these assumptions. These communities have formed on the agricultural frontier, and many are no more than 20 to 30 years old. In many cases, what is officially recognised as 'community' is no more than a loose agglomeration of socially differentiated families. The composition of such communities is constantly changing, as new immigrants arrive or as established members leave to seek work in nearby urban centres or abroad. As a result of these movements, communities are becoming increasingly more heterogeneous, and mutual interests and relations of trust progressively weaker. Under such circumstances, the assumption that resource use could be regulated by community-level structures is clearly flawed.

Id. 
requirements actually endangered the enterprises' ability to generate economic returns that would benefit the region and possibly support the growth of more meaningful communities over time. ${ }^{180}$ Nonetheless, it is possible that in other situations community participation requirements will create more productive relationships between enterprises and communities and possibly help strengthen communities, as was evidently the case in Bolivia. ${ }^{181}$ However, it will always be a difficult job to figure out where and to what degree this is possible, and to create the mechanisms to bring about the desired results.

\section{c) Community Benefits}

Whether tacitly recognizing a tension between economic performance and community participation or not, regional and national standards developed to date tend to concentrate on economic benefits to communities. The Swedish standard, for example, does not mention community participation in management. Rather, it exhorts managers to support communities by practicing responsible long-term forestry, and to pay particular attention to "recreational values of forest environments for the local population."182 The Maritime standard stresses employment and other benefits to the community, and operation of enterprises to avoid or minimize damage to other community activities. ${ }^{183}$ The same is true of the

\footnotetext{
180 See id.

181 See Markopoulos, Bolivia, supra note 66, at 43. Indeed, in principle it is even possible that certification processes promoting community forestry could contribute to the establishment of communities, where none or only the rudiments previously existed. Integrated economic activity has often been the basis for the formation and integration of local communities, and there is no inherent reason why it could not be so in developing countries. See ROLAND L. WARREN, THE COMMUNITY IN AMERICA (2nd ed. 1972).

182 Swedish FSC Standard, supra note 54, $\S 4.3$

183 See Maritime Standards, supra note 54, $\S$ 4.1-4.5.
} 
British standard. ${ }^{184}$ Given their modest nature, it seems unlikely that these criteria will have large effects on enterprise-community relationships. Nonetheless, they do express a recognition of some level of responsibility to the local community on the part of the forest enterprise.

In sum, the possible effects of certification on community run from reinforcing responsible business practices to requiring serious, decision-influencing dialogues between forest enterprises and the communities. The location of FSC certification on the continuum is likely to vary by region and culture. No matter where the process occurs, however, achieving serious dialogue between enterprises and communities is likely to require developing new relationships and decision making processes. Moreover, that process may involve strengthening or even creating communities, and not merely giving preexisting communities access to decision making. Markopoulous' study of Bolivia, for example, suggests that the certification process identified weaknesses in social and political relations, and led to some important improvements over time. ${ }^{185}$ On the other hand, as his study of Honduras suggests, improving community relationships can be difficult where the economic viability of forest enterprises and the social viability of communities is weak. ${ }^{186}$ Thus, certification in developing communities will require sophisticated judgments about local social capacity and how best to build it. Certification will also require deciding to what degree communities should be directly involved in operational decisions and to what extent their interests should be protected by involvement in policy and rulemaking. For these reasons, however, the community aspect of certification may be one of the most intellectually and politically fertile in years to come.

184 Endorsed FSC Standard for Great Britain, $\S \S 4.1-4$ (Oct. 1998) <http://www.fsc-uk.demon.co.uk/Standards5th.html>.

185 See Markopoulos, Bolivia, supra note 66, at 43.

186 See Markopoulos, Honduras, supra note 178. 


\section{The International Organization for Standardization}

\section{A. Mission and Organization}

Founded in $1947,{ }^{187}$ the International Organization for Standardization (ISO) is the oldest and largest player in the private environmental regulatory arena. Its mission is "to promote the development of standardization and related activities in the world with a view to facilitating international exchanges of goods and services, and to developing cooperation in the spheres of intellectual, scientific, technological and economic activity." ${ }^{188}$ It does this largely through the publication of certification standards, guidance documents, and technical reports, of which there are thousands on subjects varying from screw threads to in-vitro testing. ${ }^{189}$

The ISO is organized as a federation of more than 130 nationally-based standard setting bodies. ${ }^{190}$ The national organizations are usually incorporated under public law, but do not operate as government agencies. ${ }^{191}$ Most ground-level standard development is done in over 200 subject-specific technical committees, which are further broken down into subcommittees and

187

It also had a predecessor organization called the International Federation of the National Standardising Associations (ISA), which was founded in 1926 but ceased operation early in World War II. See Pierre Hauselmann, ISO Inside Out: ISO and Environmental Management, WWF International Discussion Paper(1997) at 4.

188 ISO, Memento 1997 at 3, quoted in Elliott, Forest Certification, supra note 8 , at 28 .

189 See ISO website catalog <http://www.iso.ch/projects/ics.html $>$.

190 See generally the ISO website, <http://www.iso.ch/infoe/intro.htm>. There are currently about 90 "member bodies"-- national organizations taken to be most representative of standardization in their countries. There are also about eleven "subscriber members" from countries with less developed economies and 37 "correspondent members" from countries that do not have fully developed standards bodies. Id. The American National Standards Institute (ANSI) is the official U.S. member body in ISO.

191 See Hauselmann, supra note 187 , at 4. 
working groups. National organizations often form technical advisory groups (TAGs) to provide input to technical committees. ISO's annual operating budget is over $\$ 125$ million US. ${ }^{192}$

Early in its history the ISO concentrated on setting standards for products such as metal bolts and photographic film. More recently it has set standards for automatic teller machines and phone cards. After decades of largely unheralded expansion, the ISO turned its focus to production processes and systems - including management systems. It established an initial management system requirement in the late 1980s, as part of a larger set of "ISO 9000 " quality procedures and practices standards. These standards were the first to apply to many types of industries, and to be built essentially from scratch. ${ }^{193}$ They quickly became "de facto requirements" for doing business in Europe and other parts of the world. ${ }^{194}$

An important impetus in the rapid development of the ISO environmental standards was the desire of multi-national corporations to head off a flurry of national environmental standard setting initiatives, some focusing on management systems, others on information disclosure. ${ }^{195}$ The ISO organization also took the opportunity provided by the 1992 Rio Conference on Environment and Development to "do something" for the environment. ${ }^{196}$ Shortly after the conference, the ISO's Strategic Action Group on the Environment ("SAGE") concluded that an ISO environmental standard could contribute to world standardization, improve

\footnotetext{
$192 \quad$ See id. at 5.

193 See Naomi Roht-Arriaza, Private Voluntary Standard-Setting, the International Organization for Standardization, and International Environmental Lawmaking, in GÜNTHER HANDL, 6 YRBK OF INT. ENVTL. L. 107, 119 (1995). 194 See id. ISO 9000 certification was required for a number of regulated products covered by EC directives, and also to sell to government controlled entities throughout Europe. Some U.S. government agencies also add it to their procurement requirements. See $i d$ at 120.

195 See Jennifer Nash \& John Ehrenfeld, Code Green: Business Adopts Voluntary Environmental Standards, 38 ENV'T 16-45 (1996).

$196 \quad$ See id. See also infra note 29.
} 
environmental performance, and facilitate world trade. ${ }^{197}$ The ISO then decided to establish a new committee on environmental management to begin promulgating series "ISO 14000" environmental standards and guidelines. The committee, Technical Committee 207 (TC207), operates independently of TC 176, which produced the ISO 9000 series.

The primary standard, ISO 14001, was completed in $1997 .{ }^{198}$ It establishes the firm as the primary mover in environmental policy, and the environmental management system as the primary mechanism. It contains no substantive, performance-based criteria. Proposals for sector-specific standards were rejected early in the development process, ${ }^{199}$ as were suggestions for general substantive standards, such as best management practice or best available technology, which American representatives in particular worried might lead to increased civil or criminal liability. ${ }^{200}$

197

See Tom Tibor \& Ira Feldman, ISO 14000: A GUIDE TO THE NEW ENVIRONMENTAL MANAGEMENT STANDARDS 32 (1995).

198 TC 207 working groups have also established a number of guidelines for ISO related processes, including guidelines for (a) environmental auditing (ISO $14010,14011,14012$ ), (b) environmental assessments of sites and entities(ISO 14015), (c) guidelines for environmental labels and declarations (ISO $14020,21,24,25$ ), (d) environmental performance evaluation (ISO 14031), (e) life cycle assessment (ISO 14040, 14041, 14042, 14043), and (f) vocabulary (ISO 14050). These guidelines are formally non-binding, but are expected to have a significant effect on corporate information gathering and decision making over time. See generally American National Standards Institute Website, $<\mathrm{http} / /$ www.ansi.org/public/iso14000/docs_6.html>. It should be noted that the labeling guidelines, some of which are still being developed and which are not reviewed in any detail this article (in particular ISO 14025, applicable to third party certification), could have a significant effect on environmental certification programs.

${ }_{199}$ Proposals for a forestry-specific standard were rejected, but had enough strength to generate a special working group. See Roht-Arriaza, supra note 193, at 158. The working group produced a report in 1998: ISO/TR 14061, Information to Assist Forestry Organizations in the Use of Environmental Management System Standards ISO 14001 and 14004.

See id. at 124. 


\section{B. Program Elements}

\section{Firm-Centered Environmental Policy}

ISO 14001 is unambiguous about the center of environmental policy-making. While environmental law is treated as a given, new policy development occurs in the firm.

\subsection{Environmental Policy [emphasis added]}

Top management shall define the organization's environmental policy and ensure that it

a) is appropriate to the nature, scale and environmental impacts of its activities, products or services;

b) includes a commitment to continual improvement and prevention of pollution;

c) includes a commitment to comply with relevant environmental legislation and regulations, and with other requirements to which the organization subscribes;

d) provides the framework for setting and reviewing environmental objectives and targets;

e) is documented, implemented and maintained and communicated to all employees;

f) is available to the public. ${ }^{201}$

201 ISO, International Standard 14001, Environmental management systems-Specification with guidance for use, $\S 4.2$. 


\section{Environmental Management System}

The crown jewel of the ISO 14000 regime is the environmental management system (EMS) defined in Section 14001; the other ISO 14000 series guidelines seek to clarify possible ways of operating the EMS. Practitioners talk in terms of "installing an environmental management system" in the organization, ${ }^{202}$ thus invoking an image of the firm as a machine that can be redesigned and rebuilt to maximize selected functions. ${ }^{203}$ As noted in the FSC section, the basic idea of an EMS is to have organizational arrangements for setting environmental goals, pursuing them, monitoring achievement, and revising goals and plans. Accordingly, the EMS can be conceptualized as a series of components for planning, implementation, monitoring, and corrective action. An EMS need not be installed in an entire company, but rather may be installed in a "single operating unit."204

\section{a) Planning}

The planning component must identify all environmental aspects of the organization's activities, catalogue all applicable environmental legal and other requirements, set and document environmental objectives and targets, ${ }^{205}$ and establish a program for achieving them. ${ }^{206}$ The organization is to consider the views of interested parties in setting objectives, but the standard does not

See J.L. Hutchins, ISO 14000 Environmental Management Systems -Current Developments, 5 ILL. ENVTL. L. LTR. 22-26 (1996); Christopher Sheldon \& Mark Yoxon, INSTALLING ENVIRONMENTAL MANAGEMENT SYSTEMS: A STEPBY-STEP GUIDE (1998).

203 Any such redesign must be done within the general framework of maximizing shareholder wealth, of course.

204 ISO $14000 \$ 3.1 .2$. "Operating unit" is not defined in the standard.

205 The objectives are to be specific, and the targets measurable wherever practicable. See ISO 14000 Annex A, § A.3.3.

206 See ISO, International Standard 14001, supra note 201, §§ 4.3.1-4.3.4. 
indicate on what information interested parties will base their views. ${ }^{207}$ "Environmental aspects" are broadly defined to include all of the organization's interactions with the environment, ${ }^{208}$ but the organization need not disclose information on them to the public. Examples of potentially applicable "other requirements" than legal ones include industry codes of practice and agreements with public authorities. ${ }^{209}$ The program must assign responsibility for reaching objectives and targets to particular parts of the organization and include means and a time frame. ${ }^{210}$

\section{b) Implementation and operation}

The implemented EMS must define, document, and communicate management roles, responsibilities and authorities. ${ }^{211}$ The organization is to provide essential resources for implementation, including financial, technical and human ones, and must also designate officers responsible for overall implementation of the EMS and reporting on its performance. ${ }^{212}$ The EMS must also provide for

See id. § 4.3.3. "Interested party" is defined as "an individual or group concerned with or affected by the environmental performance of an organization." Id. § 3.1.1

208 Related "guidance" documents detail the environmental review process (ISO 14004), elements of environmental auditing (the ISO 14010 series), environmental site assessment(ISO 14015), environmental labeling (the ISO 14020 series), environmental management performance evaluation (ISO 14031, 14032), environmental life cycle assessment (the ISO 14040 series) and terms and definitions (ISO 14050).

209 See ISO 14000 Annex A, § A.3.2.

210 See ISO, International Standard 14001, supra note 201, §4.3.4. Although ISO is developing non-binding product "life-cycle" guidelines, the environmental management system standard only applies to "those environmental aspects which the organization can control and over which it can be expected to have an influence." ISO 14001:1996(E) $\$ 1$

211 See ISO, International Standard 14001, suprá note 201, § 4.4.1.

212 See id. 
employee training, ${ }^{213}$ internal and external communication procedures, ${ }^{214}$ and for up-to-date, accessible documentation. ${ }^{215}$ The organization must identify operations necessary to success, and procedures for their control. ${ }^{216}$ Finally, the organization must establish and maintain a system for responding to emergencies, and for preventing or mitigating associated environmental impacts. ${ }^{217}$ It must also test emergency procedures periodically and review and revise them whenever any emergencies occur. ${ }^{218}$

Importantly, as many commentators have pointed out, the EMS is not required to achieve compliance with legal and other requirements, only to attempt to do so. This possibility was vividly illustrated recently when an American company announced that it had achieved ISO 14001 certification on the same day that it was served with notices of Clean Air Act violations by the Environmental Protection Agency. ${ }^{219}$

\section{c) Monitoring}

Information production and monitoring are given an important role in the system:

The organization shall establish and maintain documented procedures to monitor and measure, on a

See id. $\S 4.4 .2$

See id. $\S 4.4 .3$

See id. $\S \S 4.4 .4,4.4 .5$

See id. $\S 4.4 .6$

See id. $\S 4.4 .7$

See id.

See Jennifer Shapira, PA Company Violatès Clean Air Act, Certifies to ISO 14001, INT'L ENVTL. SYS. UPDATE, 6(6) 8-8 (June 1999). To some degree, this illustrates the distinction between an environmental management system and an environmental compliance system, but it is quite unlikely that even a compliance system would achieve perfect compliance. 
regular basis, the key characteristics of its operations and activities that can have a significant impact ${ }^{220}$ on the environment. This shall include the recording of information to track performance, relevant operational controls and conformance with the organizations environmental objectives and targets. ${ }^{221}$

The organization is specifically required to "establish and maintain a documented procedure for periodically evaluating compliance with relevant environmental legislation and regulations"222 and to maintain records of the monitoring process "according to the organization's procedures." ${ }^{\text {223 }}$ These records need not be made publicly available. ${ }^{224}$

220 "Significant impact" is not defined in the standard. It is clear only that not every environmental impact need be significant, and that not every "environmental aspect" need be an "environmental impact." Much discussion is underway among practitioners regarding how to operationally define these terms.

221 ISO, International Standard 14001, supra note 201, § 4.5.1.

222 Id.

$223 \quad I d$.

224 This is in direct contrast to the British provision which served as the model for the ISO 14001. The BS 7750 Standard requires the organization to maintain a public register of significant direct and indirect effects of products, activities, and services. See Roht-Arriaza, supra note 193, at 125 . There are also other efforts to create standardized information disclosure. The Coalition for Environmentally Responsible Economies (CERES), for example, which had been working for some time on a global initiative to encourage companies to use standardized measurement methods for activities such as product performance, energy use, and non-product output, recently joined with a number of other efforts in the Global Reporting Initiative, which is working to develop a comprehensive set of "sustainability" indicators (not just environmental ones). See Kara Sissell, Management Systems Win Over Regulators, 161 CHEM. WK. 37 (Apr. 14, 1999). See generally the GRI website <http://www.globalreporting.org>. 


\section{d) Corrective Action}

The organization must have procedures for "defining responsibility and authority for handling and investigating nonconformance," as well as for taking mitigating and corrective action. ${ }^{225}$

\section{e) EMS Audit}

The firm must "establish and maintain programme(s) and procedures for periodic environmental management system audits. "226 It must also periodically evaluate its compliance with environmental laws and regulations. ${ }^{227}$ The audits are to determine whether the EMS conforms to planned arrangements and has been properly implemented. The procedures must cover "audit scope, frequency and procedures," as well as responsibilities for conducting and reporting audits. ${ }^{228}$

The standard does not specify who is to conduct the audit, and allows for both internal and external (third-party) audits. ${ }^{229}$ Moreover, most ISO practitioners make a firm distinction between an EMS audit and an audit of legal compliance, ${ }^{230}$ although the USEPA and the Multi-State Working Group on Environmental Management Systems are also trying to "blend" the two concepts. ${ }^{231}$

225 See ISO, International Standard 14001, supra note 201, \$4.5.2.

$226 \quad$ Id. $\S 4.5 .4 \mathrm{~b}$.

$227 \quad$ See id. $\$ 4.5 .1$.

228 See id.

229 See id. See also §A.5.4 of the Annex, which is "informative," rather than binding: "Audits may be performed by personnel from within the organization and/or by external persons selected by the organization. In either case, the persons conducting the audit should be in a position to do so impartially and objectively." 230 E.g., Jack Kanholm, ISO REQUIREMENTS: 61 REQUIREMENTS CHECKLIST AND COMPLIANCE GUIDE (1998).

231 Multi-State Working Group on Environmental Management Systems, EMSs, Environmental Performance, and Compliance (Dec. 13, 1999) <http://www.dep.state.pa.us/dep/deputate/pollprev/mswg/compliance.htm>. 


\section{f) Management Review}

Top management is required to review the EMS to "ensure its continuing suitability, adequacy and effectiveness." ${ }^{132}$ The review must consider the need for changes to "policy, objectives and other elements" of the EMS in light of audit results, changing circumstances, and the commitment to continual improvement.

\section{Continual Improvement}

The primary goal-based driver in the standard is the requirement that the organization design the EMS to pursue continual improvement, which is defined as a "process of enhancing the environmental management system to achieve improvements in line with the organization's environmental policy. "233 The standard explicitly provides that the "process need not take place in all areas of activity simultaneously. ${ }^{1234}$ Also, it should be noted that it is the EMS that is to be continually improved - not environmental performance. This policy was a source of intense debate during the drafting process, with European delegations advocating a performance-based criterion, and U.S. and some other delegations advocating a management system criterion for continual improvement. ${ }^{235}$ It is possible, however, that the standard as written will eventually be taken to require improved performance. The argument would be that because an EMS includes objectives and targets, an improved EMS will necessarily include improved objectives and targets, and that a properly implemented system will necessarily advance toward them. Whether this possibility is realized will be important to watch.

ISO, International Standard 14001, supra note 201, § 4.6 Id. § 3.1 .

Id.

See Roht-Arriaza, supra note 193, at 122. 


\section{Prevention of Pollution}

The standard also includes a commitment to "prevention of pollution," which is defined as "use of processes, practices, materials or products that avoid, reduce or control pollution, which may include recycling, treatment, process changes, control mechanisms, efficient use of resources and material substitution. ${ }^{1236}$ This provision is quite controversial because it allows for the possibility of using so-called "end-of-pipe" technologies to reduce pollution, as well as input changes, process changes and the like. ${ }^{237}$

\section{Auditing and Registration}

Although firms are not required to use third-party auditors, they must do so in most countries if they wish to register themselves as certified. The ISO has fairly elaborate arrangements for the accreditation of certifiers. These are handled by the national member bodies, often through contracts with accreditation firms. ${ }^{238}$ There are currently 22 accredited certifiers in the US, and nine additional applicants for accreditation. ${ }^{239}$

236 ISO, International Standard 14001, supra note 201, § 3.13.

237 E.g., Joel A. Tickner, ISO 14,000: Will It Deter Cleaner Production? 8 NEW SOLUTIONS 285-308 (1998).

238 See Stephen Bass, FSC and ISO Approaches to Forest Certification: $A$ Comparison and Suggested Ways Forward (DG-VIII Forest Certification Advisory Group, Forest Certification Note 2, 1997) $<$ http://www.efi.fi/publications/Discussion_Papers/01.pdf $>$.

239 See Registrar Accreditation Board Website, $<$ http://www.rabnet.com/cgi/>. EPA has also funded establishment of a blue ribbon panel to review the operation and rigor of the ANSI/RAB accreditation process, but no results are publicly available at this writing. 


\section{Program Operation}

\section{Standard Setting}

\section{a) By the ISO}

As noted above, most ISO standard setting work is done through technical committees, subcommittees, technical advisory groups, and working groups. The Technical Committee developing the 14000 series, TC207, has a membership including 85 national bodies; fewer than forty, however, have participated with any frequency. ${ }^{240}$ TC207's work is divided among the main committee and six subcommittees: Environmental Management Systems(EMS), Environmental Auditing and Related Investigations (EA\&RI), Environmental Labels and Declarations (EL), Environmental Performance Evaluation (EPE), Life Cycle Assessment (LCA), and Terms and Definitions (T\&D). ${ }^{241}$ Most of the subcommittees have completed some guidance documents and are currently working on others in their areas of interest. The guidance documents are not binding for certification purposes, but are nonetheless expected to be influential in shaping the implementation of ISO 14001. The subcommittees' drafting efforts are augmented by approximately 18 working groups, which do much of the initial drafting work. ${ }^{242}$

The very complexity of the TC207 organization makes its work difficult to follow. Doing so would require a relatively wellfunded, sophisticated organization. Early on, corporate interests from large industrialized countries dominated the ISO 14000 drafting process. ${ }^{243}$ Over time, more governments, developing countries, and NGOs became involved, but by then many of the fundamental

Personal observations and communications. 
decisions had been made. ${ }^{244}$ In principle, the national standard setting organizations represented on the technical committees are responsible for convening balanced sets of interests and bringing their input into the writing process, ${ }^{245}$ but it is not clear how many do so, or how often. ${ }^{246}$ In the case of TC207, it appears that much decision making was done by people who could participate regularly and intensively in the drafting process, and that these were often representatives of large, transnational corporations. ${ }^{247}$ This makes sense because transnational corporations are most likely to have a strong interest in international standardization, as well as in the organizational and financial resources necessary to participate effectively in a process scattered among many sub-committees and working groups meeting in many different countries. Governmental agencies and NGOs, by contrast, are likely to have more pressing priorities for the use of tight budgets.

The dominance of large corporations did not prevent conflict in the drafting process, since corporations often have conflicting interests in different types of standards. Indeed, although the ISO seeks to operate on a consensus basis, ${ }^{248}$ the TC207 processes have often been sufficiently contentious to require votes. ${ }^{249}$ Virtually every word of the ISO 14001 standard was vigorously fought over. On the whole, environmental requirements were softened as time went on,

\footnotetext{
$244 \quad$ See id.

245 See id. at 140.

246 In a pioneering study that does not appear to have been replicated in the U.S. or elsewhere, Hamilton found performance in the American context quite inconsistent. See Robert J. Hamilton, The Role of Nongovernmental Standards in the Development of Mandatory Federal Standards Affecting Safety or Health, 56 TEX. L. REV. 1329 (1978).

247 See Roht-Arriaza, supra note 193, at 41.

248 Consensus is defined as "general agreement, characterised by the absence of sustained opposition to substantial issues by any important part of the concerned interests and by a process that involves seeking to take into account the views of all parties concerned and to reconcile any conflicting arguments. Note: consensus need not imply unanimity." Elliott, Forest Certification, supra note 8, at 36.

249 See id at 10-11.
} 
often at the insistence of American or Asian firms. Examples include the decision to require firms to commit to complying with applicable legislation, rather than to comply with environmental laws; to require "continual improvement" of the environmental management system, rather than of environmental performance,;50 and to define "prevention of pollution" as including end-of-pipe technologies.

\section{b) By the Firm}

Because firms are the primary locus of substantive policymaking in the ISO system, they will be the primary source of substantive standards in the ISO system. Thus, the standards that they set in defining their plans, targets and objectives, will be crucial in determining the impact of the system. Although many thousands of firms are ISO 14000 certified, ${ }^{251}$ research for this article uncovered no systematic information on their environmental policies and practices. Until such research is done, it will be impossible to say much about ISO standard setting.

For now assessments must be based on a general understanding of how firms operate. It therefore seems likely that standards will vary greatly depending on firms' internal cultures and their external environments. External forces are likely to be particularly important determinants of firm policies. Since firms must publish their environmental policies, those located in areas with sophisticated citizens' groups may feel effective pressure to

2so In forestry there has been considerable debate about the practical meaning of "continuous improvement." Part of the debate is whether the standard should improving on -- sometimes abysmal -- current practices or the degree of progress toward ideal ones. In addition, there is the problem of what should be counted: limits on clear cut areas, riparian buffer zones, use of wide-flotation tires, use of remote sensing, etc. It is often pointed out that the overall condition of forests worldwide is declining, and could easily continue to do so even as firms were achieving "continuous improvement" from primitive practices.

251 Over 13,000 firms had been registered as of the end of 1999. See ISO World Website, <http://www.ecology.or.jp/isoworld/english/analy $14 \mathrm{k} . \mathrm{htm}>$. 
promulgate policies demonstrating real environmental improvement, rather than desultory improvements in their environmental management systems. On the other hand, the fact that firms need not reveal any information about their operations may limit the effectiveness of citizens' groups, particularly in jurisdictions lacking strong right-to-know laws.

A second category of factors potentially influencing firms to establish strong policies is financial. Firms seeking external financing, good insurance rates, and new investors may be inclined to develop strong environmental policies in order to enhance their strength in the marketplace.

A third potential influence is the process of general discussion and deliberation among certifiers, trade-associations, etc., which over time could lead to relatively uniform standards and practices across geographic areas. Whether and to what degree this might be happening, however, is currently unknown, and it is counterbalanced by the pressure on certifiers to meet the particularized expectations of individual clients and preserve their confidentiality.

A final potential influence is regulatory. Firms may wish to impress regulatory agencies with their environmental policies so as to reduce their risks of inspection or even the standards they must meet. Some states have already developed policies that accord special treatment to firms achieving ISO $14001 .^{252}$ The EPA is also developing a program that places special emphasis on environmental

For example, the Connecticut "Act Concerning Exemplary Environmental Management Systems" provides companies (1) with registered ISO 14001 environmental management systems, (2) that have adopted approved principles of sustainability, and (3) that have good compliance records with: expedited permit review, reduced fees, less frequent reporting, a facility wide permit for all approvals, and public recognition of having attained this achievement. Connecticut Public Act Number 99-226, June 29, 1999 <http://www.cga.state.ct.us/ps99/Act/pa/1999PA-00226-R00HB-06830-PA.htm>. This provision came to my attention through the "voluntary codes" list-serve maintained by Kernaghan Webb, a valuable source of information which can be accessed at <http://strategis.ic.gc.ca/SSG/ca00973e.html>. 
management systems. ${ }^{253}$ Given the scope of the phenomenon and the complexity of the questions, it will take much time and research to determine whether and in what circumstances any of these factors lead to significant changes in firms' environmental policies.

\section{Certification Process}

To date, approximately 15,000 companies world-wide have been registered as ISO 14001 certified. Most of them are concentrated in Asia and Western Europe. ${ }^{254}$ Japan leads the world with over 2,500 certified companies. ${ }^{255}$ Certification apparently costs anywhere from $\$ 10,000$ for a small company, to $\$ 50,000$ to $\$ 100,000$ for a mediumsized company, ${ }^{256}$ to $\$ 100,000$ to $\$ 1$ million for a large one. ${ }^{257}$ As with the FSC process, the general contours of the certification process are known, since they follow the standard itself, yet relatively little is known about how certification actually works, or how it might change firms' behavior. Some research is underway to learn about the workings of the certification process, ${ }^{258}$ but the standard's protection of firm confidentiality, and the interests of both firms and certifiers in retaining confidentiality, will make progress slow.

\footnotetext{
${ }^{253}$ See USEPA Office of Pollution Prevention, $<$ http://www.epa.gov/perftrac/index.htm>.

${ }^{254}$ See ISO World Website,

<http://www.ecology.or.jp/isoworld/english/analyl4k.htm>.

${ }_{255}$ See id.

256 See Tickner, supra note 237, at 296.

257 See James Cohen, More than 4000 Companies Certified Under ISO 14001: Japan, Europe Lead Way, 21 INT'L ENVTL.. REP. 650 (1998)

258 The U.S. Environmental Protection Agency, for example, is funding a major project by the Environmental Law Institute and the University of North Carolina. See Richard Andrews et al., The Effects of ISO 14001 Environmental Management Systems on the Environmental and Economic Performance of Organizations (Project Summary 1, March 27, 1999) (on file with author).
} 


\section{Implications for Environment, Human Rights, and Community}

\section{Environment}

Given the limited information about the actual workings of the ISO 14000 system, inferences regarding its environmental effects are tricky at best. It does seem clear that the system is expanding. Several scholars have described it as a "de facto requirement for doing business" around the world, ${ }^{259}$ though this assessment may be a bit premature. Some governments seem likely to make compliance with ISO standards a prerequisite to doing business in their jurisdictions (perhaps the most important example being the European Union). The South African government made certification a condition of privatization for Sappi, the largest forestry company in South Africa. ${ }^{260}$ Many governmental agencies, including some in the US, are adding ISO 14001 certification to their purchasing criteria and establishing other programs that promote ISO compliance. ${ }^{261}$ Some courts have ordered companies to comply with ISO standards as remedies for violations of domestic environmental laws that do not mandate ISO performance levels. ${ }^{262} \mathrm{~A}$ number of major corporations, including Ford Motor Company, have announced that, in addition to having all of their own operations certified, they

259 See Virginia Haufler, Private Sector International Regimes, 4 PoLIBUS 1 (1998); Tickner, supra note 237, at 286.

$260 \quad$ See Thornber, Equity and Certification, supra note 18.

261 See Roht-Arriaza, supra note 193, at 149. See also Meidinger, Incorporating Certification Systems, supra note 132.

262 See Kernaghan Webb, Voluntary Initiatives and the Law, in VoLUNTARY INITIATIVES AND THE NEW POLITICS OF CORPORATE GREENING (R. Gibson ed., 1998); Meidinger, Incorporating Certification Systems, supra note 132. 
will require all of their suppliers to be ISO certified in the next few years. ${ }^{263}$ The World Trade Organization also strongly favors ISO standards, since they are by definition international and ostensibly consensual. ${ }^{264}$

While the growing influence of the ISO certification seems clear, what effect it will have on environmental protection is less clear. The system relies almost entirely on the effects of installing an EMS in the firm. The key elements of an EMS are:

1. Production and analysis of extensive information on the firm's environmental effects (but retention of that information inside the firm);

2. Integration of environmental goals into general management systems;

3. Continuous improvement in the environmental management system; and

4. Response to public comments on the firm's environmental management policy.

Because it contains no substantive environmental standards, some commentators have argued that "on its own, ISO 14001 cannot achieve sustainable industrial development or even environmental performance improvement." 265 This is probably an overly legalistic judgment, which equates performance with outcome requirements and fails to give due weight to organizational dynamics. It is hard to believe that no firms will improve their environmental practices after

See Ford Motor Company Press Release, Sept. 21, 1999, $<$ http://www.tqm.com/wwwboard/msgs/811.html>. IBM and Xerox are also seeking certification of all their operations and pushing their suppliers to do the same. See 161 CHEM. WK. 37 (Apr. 14, 1999).

E.g., Hauselman, supra note 187.

265 RIVA KRUT \& HARRIS GLECKMAN, ISO 14001: A MISSED OPPORTUNITY FOR SUSTAINABLE GLOBAL INDUSTRIAL DEVELOPMENT 25 (1998). 
gathering extensive information on their environmental aspects and impacts, integrating environmental goals into their management systems, and responding to public comments on their environmental policies. Certainly some firms will be moved to make improvements as a result of better information, management coordination, or increased public pressure. Moreover, the ISO program requires a firm to look at all of its environmental aspects, not just those regulated by law. This is important because environmental laws are almost always underinclusive, and firms may address problems through their environmental management systems for which there are no substantive legal or other standards. Still, it is impossible to say how much improvement will occur, and even more difficult to say where it will occur, since firms may make very different choices regarding environmental goals depending on their local and financial situations.

The main way for the ISO system to yield predictable environmental gains is for it to be linked to substantive standards. Such linkage could happen in any of several ways. First, of course, firms could embrace substantive standards. Indeed, there has been considerable discussion about possible linkages between the ISO and substantive systems. ${ }^{266}$ The American Forest \& Paper Association's Sustainable Forestry Initiative (SFI), in particular, publicly promotes its standard as compatible with the ISO 14000 standard, as do the Canadian Standards Association and the Pan European Forest Certification Council (PEFC) ${ }^{267}$ Such linkages can be made through the "other requirements" provision of Section 4.2(c), as discussed

E.g., Ira R. Feldman, Feldman, ISO 14000 Advocate Answers Krut's Critique, Suggests "Sustainability" Role for International Standard, ENVTL. L. AND PRAC., Spring 1999; Elliott \& Hackman, supra note 16; KRUT \& GLECKMAN, supra note 265; Dick Hortensius, ISO 14000 and Forestry Management - ISO Develops 'Bridging', ISO TC207 Webpage, <http://www.tc207.org/articles>. TC 207 produced a technical report, ISO/TR 14061, discussing bridging in the Forest Industry. Id.

267 See supra text accompanying note 5. The Canadian Standards Association has also developed a forestry standard intended to be linked to ISO 14001 certification. See Elliott, Forest Certification, supra note 8. 
above, as well as through the requirements that the views of interested parties be considered. Firms could also simply incorporate them in their environmental targets. In practice, several major European forestry firms, including AssiDomain and Korsnäs, have combined ISO 14001 and FSC certification. ${ }^{268}$ AssiDomain has taken the position that the FSC and ISO standards are not only compatible, but also complementary. ${ }^{269}$ Whether voluntary linkage becomes widespread, however, remains to be seen. For now there appear to be relatively few examples of it being done.

Substantive standards could also be imposed by law, and of course existing legal standards are already incorporated in a soft way through the commitment to comply with applicable laws. It is possible that governments could define legal requirements specifically applicable to firms seeking ISO 14000 certification in their jurisdictions, but research to date has uncovered no examples of that being done.

In sum, the ISO 14000 system's effects on environmental protection are quantitatively indeterminate for the present and will be for some time. Because of the organizational dynamics put in play, however, it seems likely that the system will have positive environmental effects in the companies that adopt it. Although it is reasonable to assume that the mere collection and review of information on the environmental implications of firm behavior may lead to changed behavior, there seems to be very little research on when and how firm behavior actually changes. Indeed, research by King and Lennox on the American chemical industry's Responsible Care program gives reason for pause, since it finds no superiority of participating over nonparticipating firms, and indeed contains some

268 See Hortensius, supra note 266.

269 See Alan Pierce \& Spencer Phillips, FSC-Certified: A New Standard for Environmentally Responsible Paper, at 14 (The Wilderness Soc'y, Ecology \& Econ. Res., Occasional Paper VT-90-01) (on file with author). 


\section{9-2000] PRIVATE ENVIRONMENTAL REGULATION 203}

evidence that they may have lagged. ${ }^{270}$ Moreover, depending on how much environmental policy making is removed from the public domain into corporate decision making, it is possible that in the long term the effects of the ISO initiative will be seen as negative. The argument would be that focused state regulation would have achieved greater progress, and could well lead to renewed and intensified public regulation.

\section{Human Rights}

The ISO 14000 system does not directly address matters that would normally be classified as human rights concerns. The introductory section of 14001 states that it does not include occupational safety and health issues, but is not intended to "discourage" organizations from incorporating them in their management systems either. The structural de-linking of environmental from health and safety concerns seems curious, especially since many corporations seem to have been moving toward linking them in their management structures in recent years. ${ }^{271}$ Overall, it is hard to see the ISO system as a significant step for human rights. The only way a positive human rights effect can be inferred is to the degree that "better" management is correlated with better human rights treatment -- an uncertain proposition at best.

\section{Community}

As noted above, the overall thrust of the ISO 14000 system is to commit as much environmental decision making as possible to the firm. The firm has no substantive duties to the community, and the community role in decision making is limited to commenting on the

See Andrew King \& Michael Lenox, Industry Self-Regulation Without Sanctions: The Chemical Industry's Responsible Care Program, ACAD. OF MGMT. J. (forthcoming) (on file with author). 
company's environmental policy. Given the lack of information disclosure requirements in the ISO system, communities will often have little information about company operations upon which to base their comments. In addition, the ISO system is highly international, making it difficult for local communities to get a purchase on it. To participate effectively, communities will likely have to rely upon local laws giving them information about company operations and on the independent expertise of their members. ${ }^{272}$ Thus, on the whole it seems unlikely that the ISO system will enhance the role of communities in environmental management. There are some factors that militate in the opposite direction, such as the need to clothe ISO certification with political credibility, but they all depend on factors outside the ISO system. ${ }^{273}$

272 For an example of how community advocates can use information and local laws to leverage decisional power, see R. Nils Olsen, Jr., The Concentration of Commercial Hazardous Waste Facilities in the WNY Community, 39 BuFF. L. REv. 473 (1991); Gary Abraham Concepts of Community in Environmental Discourse: Farmersville and Western New York's Garbage Wars, infra p.51 this volume.

273

The EPA is interested in "stakeholder participation ... in development and implementation" and "effect that such participation has on the public credibility of the facility's EMS implementation." Environmental Protection Agency, EPA Position Statement on Environmental Management Systems and ISO 14001 and a Request for Comments on the Nature of the Data to be Collected from Environmental Management System/ISO 14001 Pilots, 63 Fed. Reg. 12094-12097, (1998). 


\section{The American Forest and Paper Association}

\section{A. Mission and Organization}

The American Forest and Paper Association (AF\&PA) ${ }^{274}$ consists of approximately 130 major wood products and paper firms representing $85 \%$ of U.S. paper production and $90 \%$ of U.S. industrial timberland (approximately 13 percent of all US timberland). ${ }^{275}$ Its mission is "to provide [its] members with significant value in areas of business that are key to their success where an association can be more effective than individual companies."276 The AF\&PA pursues its mission by seeking to influence policy, providing a forum for discussions among members, and gathering a variety of statistics and other information. ${ }^{277}$

The AF\&PA founded the Sustainable Forestry Initiative (SFI) in 1994, in response both to the FSC and ISO programs and to declining public credibility of the forest products industry. ${ }^{278}$ There was a widespread sense among its members that they needed to do

The AF\&PA was founded in 1993, as a result of the merger of a trade association which had represented the timber industry for about a hundred years (the National Forest Products Association) and one that had represented the paper industry for even a while longer (the American Paper Institute). See AF\&PA Web Page <http://www.afandpa.org/about/about.html>.

${ }_{275}$ See Scott Berg \& Rick Cantrell, $A F \& P A$ 's SFI Program Promotes a Higher Standard of Sustainable Forestry, J. OF FORESTRY, Nov. 1999, at 33. Approximately 60 per cent of the forest land in the U.S. is located in "nonindustrial" or small-woodlot lands, and another $25 \%$ in national, state, and community forests. See Douglas Powell et al., Forest Resources of the United States (U.S. Department of Agriculture Forest Services General Technical Report RM-234, 1992).

276 AF\&PA Website <http://www.afandpa.org/about/about.html $>$.

277 See id.

278 See Errol E. Meidinger, Look Who's Making the Rules: the Roles of the FSC and ISO in International Environmental Policy, 4 HUM. ECOL. REV. 52-56 (1997); Joseph Rees, When Industries Question Their Morality: The Case of Industrial Forestry in the United States (paper presented to the Law and Society Ass'n., Aspen, CO, June 4, 1998) (on file with author). 
something to bolster their environmental credibility. At the same time, they wanted to avoid "finger pointing" and competing with each other on environmental issues. ${ }^{279}$ The SFI was the result. It is designed to be compatible with ISO 14000 certification, and some of its designers evidently expect that more and more firms will combine the two over time. ${ }^{280}$ Participation in the SFI is a prerequisite to AF\&PA membership. It is the closest thing in this study to what is often called "industry self-regulation." ${ }^{181} I$ do not use the term in this analysis, however, because it tends to obscure the conflicting groups within the program. Approximately 15 firms were evidently asked to leave the AF\&PA when SFI became a membership requirement in $1996 .{ }^{282}$ The program has changed significantly from its inception to the present. It began as an "industry code" of general principles to which members subscribed and self-certified, but has developed more institutional components over time. They are described below.

\section{B. Program Elements}

\section{Principles and Objectives}

Like the FSC, the AF\&PA requires firms to commit to certain substantive principles, such as practicing sustainable forestry and

279 Personal communications.

280 The ISO 14001 plans are most central in communications aimed at Europe (e.g., Scott Berg, Sustainable Forestry and Certification Developments in the United States, in CERTIFICATION of SUSTAINABLE FOREST MANAGEMENT IN COUNTRIES IN TRANSITION (Jiri Skoblik \& Kiri Mategjicek eds., 1998)). In the United States, although many large forest products companies are ISO 9000 certified, the forestry sector seems to prefer a general "go-slow" attitude toward the ISO 14000 series.

281 See e.g., IAN AYRES \& JOHN BRAITHWAITE, RESPONSIVE REGULATION: TRANSCENDING THE DEREGULATION DEBATE (1992).

282 See Berg \& Cantrell, supra note 275, at 33. The names of the firms involved have not been released, and some firms evidently left the organization for other reasons. Personal communications. 
protecting forest health. The principles are as follows (emphasis added):

1. To practice sustainable forestry to meet the needs of the present without compromising the ability of future generations to meet their own needs by practicing a land stewardship ethic which integrates the reforestation managing, growing, nurturing, and harvesting of trees for useful products with the conservation of soil, air and water quality, wildlife and fish habitat, and aesthetics.

2. To use in its own forests, and promote among other forest landowners, sustainable forestry practices that are economically and environmentally responsible.

3. To protect forests from wildfire, pests, diseases, and other damaging agents in order to maintain and improve long-term forest health and productivity. 4. To manage its forests and lands of special significance (e.g., biologically, geologically, or historically significant) in a manner that takes into account their unique qualities.

5. To continuously improve the practice of forest management and also to monitor, measure and report the performance of our members in achieving our commitment to sustainable forestry. ${ }^{283}$ 
These principles are given somewhat more detail in a series of objectives and performance measures that take a prescriptive format. The herbicide guideline, for example, provides as follows:

Objective 9. Continue the prudent use of forest chemicals to improve forest health and growth while protecting employees, neighbors, the public, and sensitive areas, including streamcourses and adjacent lands.

Performance Measures:

a. AF\&PA members will meet or -exceed all applicable label requirements, laws, and regulations concerning the use of fertilizers, herbicides, and other forest chemicals needed to protect forest health and increase growth. ${ }^{284}$

Others provide for prompt reforestation, use of EPA Best Management Practices to protect water quality, trying to limit clear cuts to 120 acres (48 hectares), protecting biological diversity, reporting and the like. Many of them promise to support further research.

In sum, many SFI principles and objectives sound similar to the FSC ones, but tend to have a more industry-oriented spin. The use of chemicals, for example, is portrayed as a necessary way of protecting forest health rather than as a threat to forest health. Nonetheless, the principles express a significant commitment to environmental protection and are quite a distance from the "cut and run" principles espoused by many old time forestry companies. ${ }^{285}$

Id.

See Rees, supra note 278, at 22-23. 
Notably lacking from the principles are commitments to indigenous and traditional use rights, worker safety, ${ }^{286}$ local employment, and community involvement. ${ }^{287}$

\section{Management Defined Policy}

As in the ISO system, management prerogatives are central to the SFI program, but they are protected in a more complex way. The principles and objectives often refer to company management policy. For example, each company "will define its own policies, programs, and plans to implement and achieve" the SFI principles and objectives. ${ }^{288}$ Yet the principles and objectives impose a variety of non-optional substantive standards. Those standards are themselves defined by top managers, however, since they are based on the final authority of the AF\&PA Board of Directors, who are ultimately responsible to the management of the AF\&PA's corporate members. Of course, as noted above, they may also respond to public opinion to a significant degree.

\section{Verification}

Originally, the SFI program sought to verify company compliance based solely on annual letters from company CEOs and company responses to SFI questionnaires. After AF\&PA staff members reviewed the documents, the AF\&PA publicly affirmed the

286 Worker safety is implied by the required proper handling of chemicals, and is mentioned as part of the logger education program, but is quite peripheral to the SFI program as a whole. It is also addressed by a separate set of AF\&PA principles described below, infra notes 322-23.

287 Although Objective 12 refers to "opportunities for the public and the forestry community to participate in the commitment to sustainable forestry," its performance measures are strictly limited to educational outreach from firms to communities. And "forestry community" of course can be interpreted as being limited to professionals and workers, as the SFI framework generally seems to do. 288 ISO, International Standard 14001, supra note 201, $\$ 4.1 .1$. 
compliance of member companies. ${ }^{289}$ Third-party, on-the-ground audits were purposefully excluded. In 1998, however, a "voluntary verification" program was instituted. This step evidently was taken partly on the recommendation of a newly created expert review panel. ${ }^{290}$ It also reflected the widespread sense that the SFI program did not have broad public credibility. ${ }^{291}$

The verification program now generally follows the ISO model, allowing for first-, second-, or third-party verification. All verifiers are to be "wholly independent." This criterion is not wholly defined, but for first-party verifiers it at least means not being "accountable to those directly responsible for the forestry operations. ${ }^{292}$ For third-party verifiers, it means not having provided consulting or other services to the organization being certified within the preceding year. ${ }^{293}$ The AF\&PA has also defined minimal qualifications for verifiers. Verification team members need a professional forestry degree plus two years experience, or a high school education plus five years work experience, both with "sufficient on-the-job training." ${ }^{1294}$ Verification team leaders need the same qualifications, plus either ISO 14001 accreditation or a course in auditing approved by a national standards body ${ }^{295}$ At least one

Personal communications.

290 See Statement of Expert Review Panel Chairman Paul Hansen, $19994^{\text {th }}$ Annual Progress Report, AF\&PA Sustainable Forestry Initiative, at 2.

291 Personal communications. See also statement of AF\&PA President and CEO, W. Henson Moore: "Because public expectation of environmental stewardship continues to evolve, we've developed a voluntary verification program. ..." $19994^{\text {th }}$ Annual Progress Report, AF\&PA Sustainable Forestry Initiative, at 1.

292 AF\&PA Voluntary Verification Principles and Procedures (AF\&PA-2001) $\S 6$.

293 See id.

294 AF\&PA Qualification Criteria for Verifiers (AF\&PA-2002). Years spent pursuing a professional degree can be credited against the work experience requirement.

295 See id. National standards bodies include the American national Standards Institute (ANSI), the American Standards and Testing Materials Society (ASTM), 


\section{9-2000] PRIVATE ENVIRONMENTAL REGULATION 211}

member of a third-party verification team must be a professional forester as defined by the Society of American Foresters. ${ }^{296}$ Unlike the FSC, the AF\&PA does not itself approve certifiers, and unlike the ISO, it does not have a registration system for them. The AF\&PA also has a list of indicators that might be used to operationalize the SFI objectives, although it stresses that the list is illustrative, that individual indicators will not apply to every organization, and that the list is likely to change over time. ${ }^{297}$

The organization to be verified can be either an entire firm or a distinct part of a firm that has its own functions and administration. ${ }^{298}$ In either case, the organization has a great deal of control over the verifier and the results. It chooses the verifier and must agree to the verification plan in advance; it must also approve any changes in the plan. ${ }^{299}$ The organization's confidentiality is

and the Canadian Standards Association (CSA). Such courses typically cost between $\$ 1500$ and $\$ 2500$. Personal communication.

296 See AF\&PA-2002, supra note 294, \$ 7.

297 See SFI Voluntary Verification Indicators (AF\&PA-2003) (1999).

298 See AF\&PA-2001, supra note 292, § 4. This reflects the expanded availability of the SFI system to non-members through licensing. See supra text accompanying notes $312-13$.

299 See AF\&PA-2001, supra note 292, § 8. Early indications are that firms choosing to seek verification are inclined to use big name, but also familiar firms:

Champion in particular went through a pretty meticulous interview process. They had bids from I think ten or twelve different auditing firms, and they announced that they were going with Price Waterhouse up in Vancouver, British Columbia. They had worked quite a bit with Price Waterhouse in their operations up in Canada.

And I think that's sort of an issue that's going to take care of itself. I mean the companies that are going to go third party are doing it because they want credibility. So chances are most of them are going to go with a big name, well recognized, credible, auditing firm. It's not going to make a lot of sense to go to third party if nobody's heard of the firm or it has a bad reputation.

Personal communication. 


\section{BUFFALO ENVIRONMENTAL LAW JOURNAL [Vol 7}

strictly protected, ${ }^{300}$ and it owns all verification work products. ${ }^{301}$ The lead verifier has final responsibility for determining conformance. ${ }^{302}$ Any findings of nonconformity must be "fully supported by the evidence;"1303 there is no comparable requirement for findings of conformity. The standard seems to assume that any non-conformities will be resolved by a schedule for conformity, which will result in a verification of compliance. ${ }^{304}$ Re-verification is to occur within three years after the first verification, and no later than every five years thereafter. ${ }^{305}$

Finally, at the end of 1999 the AF\&PA announced a new "inconsistent practices reporting protocol." The protocol allows loggers to submit confidential reports of "perceived violations of the SFI Standard by participants in the SFI program." ${ }^{306}$ The recipient of the reports is the secretary of the Independent Expert Review Panel, currently an independent consultant who has been quite active in American forest certification developments. $\mathrm{He}$ is to provide a "firewall" between the report filer and all other actors, and is to forward a report of the alleged inconsistency to the company involved, along with a request that it investigate, take appropriate action, and provide a written report within thirty days. The secretary is also to notify the report filer of any outcome of the report, and to provide a confidential summation of the reports filed and the recorded outcomes to the Expert Review Panel, the SFI Executive Committee,

See AF\&PA-2001, supra note 292, $\S 6$ and 8.

See id.

See id. §7.

Id. $\S 8$.

"Non-conformities shall be resolved, or recommendations shall include a schedule for resolution of non-conformities, before any declarations of conformance can be issued." Id.

305

See id.

306 SFI program Introduced Interim Inconsistent Practices Reporting Protocol (AF\&PA press release), Dec. 21, 1999, AF\&PA website $<$ ttp://www.afandpa.org/news/PressReleases/SFI_IP_rel.html>. The program is "interim" because eventually responsibility for handling inconsistent practices is to be taken over by state programs. 
and the SFI National Forum..$^{307}$ The reports apparently will not be made public.

\section{Logo}

SFI program participants (both members and licensees) are entitled to display the new SFI logo, featuring a bear and fish circling coniferous and deciduous trees. ${ }^{308}$

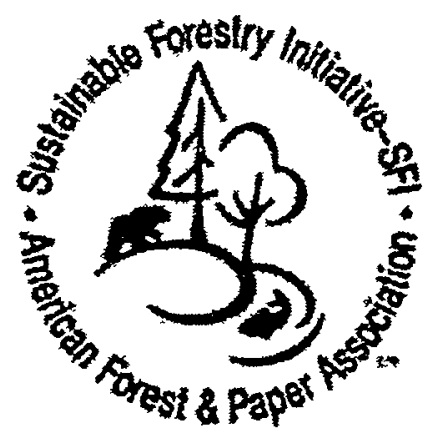

\section{Logger Training}

Rather than undertake the FSC's difficult "chain of custody" strategy, the AF\&PA is pursuing a logger education program. Loggers supplying program participants are to be taught about the SFI principles and indicators, best management practices for roads, logging sites, and streamside management, regeneration methods, Endangered Species Act requirements and other wildlife requirements. ${ }^{309}$ The program is voluntary, in part because the AF\&PA argues its members would be subject to anti-trust liability if

307 See id.

308 This logo replaces a more angular one with three conifers lined up one behind the other over a trunk with a circular arrow suggesting ecological cycles. 309

See AF\&PA Sustainable Forestry Initiative Standard, Objective 10 (1999). 


\section{BUFFALO ENVIRONMENTAL LAW JOURNAL [Vol 7}

they required supplying loggers to be trained. ${ }^{310}$ This seems a dubious argument from a legal point of view, but the organization nonetheless makes it. The SFI's goal is to give such training to all of the loggers supplying SFI participants. The AF\&PA reported that 29,000 loggers, 85 percent of the total, had taken such training by the end of 1998 , and that it expected to reach 100 percent by the end of $1999 .{ }^{311}$

\section{Licensing}

Like logger training, 'licensing' is an effort to extend the reach of the SFI program beyond SFI members. It allows nonAF\&PA members to verify to the SFI Standard and to receive SFI recognition. Upon the adoption of the licensing policy in 1998, a number of non-profit organizations (e.g., The Conservation Fund and Ida Cason Callaway Foundation) and public land management agencies (e.g., the State Forests of Massachusetts and Itasca and St. Louis Counties in Minnesota) became licensees. ${ }^{32}$ According to SFI statistics, the addition of licensee land brought the total coverage of the SFI program to "56.5 million acres [22.6 million hectares] of productive forest land in the U.S., more than any other sustainable forestry program in the world."1313

\section{Expert Review Panel}

The AF\&PA has augmented the SFI program with an eighteen member expert review panel "representing conservation, environmental, professional, academic, and public organizations. ${ }^{1314}$ The Panel's mission "is to provide a framework to conduct an independent review of the SFI program and to ensure the Annual

\footnotetext{
310 Personal communications.

$311 \quad$ See SFI $19994^{\text {th }}$ Annual Progress Report, at 8.

312 See Berg \& Cantrell, supra note 275 , at 33.

$313 \quad$ Id.

$314 \quad$ AF\&PA website <http://www.afandpa.org/forestry/sfi_frame.html $>$.
} 
Report fairly states the status of SFI program implementation. ${ }^{1315}$ While the panel lists only two members as representing environmental organizations, it includes a number of academics, state forestry officials, and past or present high level U.S. Forest Service officials. ${ }^{316}$ All in all, it appears to be a moderate panel, but it has evidently pushed the AF\&PA to attempt to measure environmental improvements resulting from the SFI program, and possibly even to consider spot audits of member management practices. ${ }^{317}$ The pressure for research on actual environmental performance is important, both to the long-term credibility of the program and to understanding how it really operates. Given the desire of panel members to protect and enhance their personal credibility, it seems

Id.

316 One participant explained the structure of the panel as follows:

You know that came about as a result of initial focus group testing that we did. You know we asked, "OK what would bring credibility to the program. Do we need to bring national environmental groups in? How do different organizations outside of the industry rate in terms of public credibility?" And it was real interesting -- and the environmental groups hate to hear it -- but one of the findings was the public kept telling us that environmental groups are good at identifying problems but by and large they are not real good at arriving at solutions. And they didn't think that we needed to bring sort of the more radical elements of the environmental groups into the program. But they did rate academics, state foresters, professional society and some of the more management oriented conservation groups, like the Conservation Fund, Nature Conservancy, high in credibility. And that sort of led us in structuring the program to add those groups to the expert review panel...

317 See Statement of Independent Expert Review Panel Chairman, Paul Hansen, and Statement of Independent Expert Review Panel, SFI $19994^{\text {th }}$ Annual Progress Report, AF\&PA Sustainable Forestry Initiative Program, at 3-6. Some panel members evidently have pushed to perform on-the-ground checks on forest practices. The AF\&PA position on this issue is that "while some members of the panel do make field visits to member companies and observe their on-the-ground practices, it is not a charge of the panel to verify practices on the ground and the panel does not review individual company data." AF\&PA Website, supra note 314. 


\section{BUFFALO ENVIRONMENTAL LAW JOURNAL [Vol 7}

likely that a substantial number of them will continue to push for improved research and information dissemination on SFI. Yet such research will have to be formally designed, proposed, permitted and financed, all difficult and time-consuming processes, which may not be completed until it is too late to document the nature or extent of change in management practices prompted by SFI.

\section{Program Operation}

\section{Standard Setting}

Standard setting has been largely internal to the AF\&PA, carried out by staff members working with interested corporate executives ${ }^{318}$ Of course they also had the FSC Principles and Criteria to work with, as well as the larger discussion of sustainable development and forestry spurred by the Rio process. In addition, they were able to draw on the history of the chemical industry's bythen well-known Responsible Care Program, which had been developed in response to the Bhopal disaster, the Rhine chemical spill, and other disasters. ${ }^{319}$ The AF\&PA tested its initial ideas on focus groups organized by a consulting firm. ${ }^{320}$ Their goal seems to have been to define a program with the minimum number of elements necessary to bolster the credibility of the American forest products industry. Although it is less clear, it appears that another important goal was to check possible inroads in North America by the more stringent, non-industry-controlled FSC program. Over time, the SFI standards have been refined, and the indicators have become a bit

318 Personal communication.

319 E.g., Neil Gunningham, Environment, Self-Regulation, and the Chemical Industry: Assessing Responsible Care, 17 L. \& PoL. 57-109 (1995).

$320 \quad$ See id. 
more demanding, as the AF\&PA has taken steps to respond to critics and to bolster the perceived credibility of its program. Such adjustments seem likely to continue in the future, given the dynamic, competitive arena of forest management certification.

\section{Verification}

The SFI program has evolved considerably beyond the simple "trust us" system it began as. However, it still requires only selfverification to achieve compliance. Moreover, even if a firm opts for third-party verification, the firm still retains a high degree of control over verifiers and their plans. No research appears to exist on any form of the verification process. Given the lack of social and policy scientists on the Expert Review Panel, such research is unlikely to be seen as a high priority within the SFI system. It will be interesting to see whether enterprising outside researchers persuade the AF\&PA to support an evaluation of the verification process. Barring that, however, we are likely to be limited to gleanings from trade journals and self-reflective musings of practitioners for some time to come.

\section{Implications for Environment, Human Rights, and Community}

While SFI began in part as a rear-guard action to halt the continuing decline in timber industry credibility while heading off more stringent regulation, it nonetheless seems to represent a significant greening of the American forest products industry. The SFI principles to which the industry has committed would have been almost unthinkable even a decade ago. The AF\&PA strategy of linking SFI to ISO certification also gives it considerable potential leverage. ${ }^{321}$ That said, much of SFI's long- term environmental effect

321 Individual companies are using this option to their advantage. International Paper Company, one of the world's largest forest products companies, combines ISO 14001 with SFI certification, and has enjoyed considerable positive 
will depend on the continuing viability of competitive systems such as the FSC, as well as continuing external pressure for improved environmental performance by the forest products industry. Institutional pressure from the Expert Review Panel will also be crucial. If these conditions hold, it seems likely that the program will play a generally positive role in environmental protection for some time to come.

An important question will be the role of SFI in defining key terms, such as "forest health," and in defining forest management standards generally, such as the use of clear cuts and chemicals. In general, as noted above, SFI has sought to inject traditional or slightly modified industry positions into the sustainable forestry debate rejecting "uneven age management," resisting old growth timber protection, defending "appropriate" clear cuts, and generally arguing for the more intensive use of industrial land (while tentatively allowing protection of other land). Some of these positions may be environmentally defensible, but it will take years to evaluate the degree to which they actually contribute to defining sustainable forestry.

The SFI program does not address human rights. Firms need not give any consideration to protecting indigenous property rights or traditional land uses, for example. However, in 1996 the AF\&PA published a separate set of "Environmental, Health, and Safety Principles. ${ }^{1323}$ They generally suggest incorporating environmental and worker health and safety concerns in business management systems by: making them "priorities;" monitoring and reporting on

publicity as a result. It recently received the 2000 World Environment Center Gold Medal for Environmental Achievement, an award that is presented by a jury of distinguished environmentalists to only one company in the world each year. See <http://www.wec.org>.

322 This implies a preference for a "cropping" approach to forestry, in which forests are made up of large areas of the same species of the same age, and are harvested at the same time.

323 See AF\&PA website,

$<$ http://www.afandpa.org/iinfo/environment/index.html\#Environment>. 
performance to corporate boards of directors; training employees; supporting research; communicating "with employees, customers, suppliers, the community, public officials, and shareholders to build greater understanding on environmental, health, and safety matters;" and participating in policymaking. ${ }^{324}$ On the whole, these principles take an ISO-like tone. They urge firms to consider many factors and develop programs, but set few substantive criteria. These principles have not received the publicity the SFI ones have, and it is impossible to know how much influence they might have on AF\&PA members.

The SFI program also mimics the ISO system by making communities tangential to the system, and centering it on the firm and forestry profession. Firms undertake no substantive duties to assist indigenous communities or protect local employment, and no procedural duties beyond outreach and education. The term "community" appears only twice in the SFI Principles and Objectives, both times referring to "the forestry community. ${ }^{1325}$ Thus, geographic communities are at most passive beneficiaries of good forest management by businesses and professionals in the SFI system. ${ }^{326}$

\section{Conclusions.}

\section{A. Patterns of Private Environmental Regulation}

The private regulatory programs described above show a number of shared and striking patterns. They were all created by groups of self-selected standard setters with relatively low levels of government and public involvement. They invoke the public interest and seek to position their participants as its trustees. They promulgate

\footnotetext{
$324 \quad I d$.

325 AF\&PA website, $<$ http://www.afandpa.org/foresatry/sfi/2000sfi_standard.html>.

326 The AF\&PA website does list "increased involvement in community forestry activities including outreach and training" as one of the benefits of $\quad \mathrm{h} \mathrm{h}$ SFI program, however. $<$ http://www.afandpa.org/forestry/sfi/sfi_report.cfm\#doingwell >.
} 
law-like texts to define their missions and to organize and legitimate their behavior. They rely heavily on expertise in interpreting and implementing their programs. They evidently assume that good principles combined with professional expertise provide solid foundations for the legitimacy of their programs.

The programs also rely on common organizational strategies, often copied from one another. Within the standard setting organizations, these include decision making based on formal constitutions and procedural rules, and organizational control based on contracts and auditing mechanisms. Beyond the standard setting organizations, more importantly, the programs seek to aggrandize the organizational capacities of the regulated entities. They do this by attempting to commit elements of firms' management systems to program goals and by monitoring the workings of the management systems. They also rely heavily on the production, analysis, and monitoring of information, combined with re-analysis and adaptation. To differing degrees, they share an implicit commitment to the proposition that improved information will lead to both organizational learning and improved control of organizational impacts on the environment. This approach to organizational control appears to be a significant step beyond the "traditional" concept of regulation represented by a simple performance rule to be met however the regulated organization chooses. In general, the systems also show a pattern of increasing stress on credible application and monitoring of standards (certification, auditing, verification, etc.). Based on the experiences of public regulatory bureaucracies in trying to maintain public credibility, this is a tendency that can be expected to continue.

Another common organizational strategy in the private environmental programs is the building of network alliances with other organizations to maximize the regulatory capacity of the programs. The FSC's key alliances are with environmental NGOs ${ }^{327}$ 
and buyers groups, as well as with FSC certified producers and sellers. ${ }^{328}$ The ISO's key alliances are with transnational corporations and the World Trade Organization, the emergent arbiter of regulation in international trade. ${ }^{329}$ The AF\&PA's central alliances are with the developed North American forestry production and manufacturing network and the forestry profession generally, whose support or opposition it can plausibly claim to be able to deliver to sustainable forestry programs. These networks are interrelated to some extent, of course, and some actors participate in several. However, they are also in competition with each other, and potentially with governments. The relationships of governments to these networks remain only partly worked out. While the private standard setting organizations have generally tried to avoid the strictures and entanglements of working with governments, effective government policy frameworks are thought by many commentators to be very important to the

programs generally, and fear that they will turn into a form of backsliding as governments focus their attention on other areas over time. Personal communications.

${ }_{328}$ It has also recently formed an alliance with five other social and environmental certification organizations. See Public Statement: Safeguarding Environmental and Social Issues in Trade (circulated by Patrick Mallet, Falls Brook Centre, Canada, December 20, 1999). The other participating organizations are:

- Council on Economic Priorities Accreditation Agency (CEPAA)

- Fairtrade Labelling Organizations (FLO) International

- International Federation of Organic Agriculture Movements (IFOAM)

- International Organic Accreditation Service (IOAS)

- Marine Stewardship Council (MSC)

Their announcement includes goals such as "an analysis of accreditation procedures leading to a common framework; a peer review process for accreditation that will enhance the transparency of these organisations; research on the overlap of standards between systems and a strategy for increasing compatibility; development of joint training programs; and further discussions on trademark use and logo proliferation."

329 See Matthias Finger \& Ludivine Tamiotti, The Emerging Linkage between the WTO and the ISO: Implications for Developing Countries (1999) (draft paper on file with author). 
effective operation of certification systems. ${ }^{330}$ Conversely, certification programs could prove important allies to government policies, and governments are increasingly participating in and relying on them. ${ }^{331}$

The programs also share important substantive commonalities. Most important is the general goal of sustainable development, to which they all profess commitment. ${ }^{332}$ They are locked in an intense competition, however, to define what sustainable development will mean in practice, and who will benefit in the near term. As part of this process, the programs show a "mimicry" dynamic, in which they borrow many of each other's elements and terms, but also seek to achieve strategic variation by offering different definitions of key terms and concepts. While this probably makes sense within the programs, it has the potential to foster considerable confusion outside them, potentially undermining them all. ${ }^{333}$

\section{B. Causes of Private Environmental Regulation}

At a recent conference of the International Forestry Students Association, a panel of experts was asked to explain the rise of forest

E.g., Bass \& Simula, supra note 5, at 34-35; Webb, supra note 262, at 43; Meidinger, Incorporating Certification Systems, supra note 132.

331 E.g., P.N. Grabosky, Green Markets: Environmental Regulation by the Private Sector, 16 L \& POL. 419 (1994). Meidinger, Incorporating Certification Systems, supra note 132.

332 See note 29 infra.

$333 \quad$ See Wilson, Uneasy Partnerships, supra note 48. Wilson portrays a situation of "copycat programs that mimic environmentally sound ones in watered down form" Id. See also Bass \& Simula, supra note 5, at 33. For a general discussion of mimicry dynamics in environmental law, see William R. Rodgers, Jr., Deception, Self-Deception, and Myth: Evaluating Long-Term Environmental Settlements, 29 U. RICH. L. REV. 567 (1995), and William R. Rodgers, Jr., Deception, Self-Deception, and Mythology: The Law of Salmon in the Pacific Northwest, 26 PAC. L.J. 821 (1995). 
certification. ${ }^{334}$ They cited three main reasons. The first was the continuing decline of the world's forests, particularly in tropical countries, but also in old growth regions of developed countries such as the US and Canada. The second was the accompanying loss of public confidence in both the forest industry and government over the last several decades. The third was fear of economic losses by both management and labor. While these factors offer the most concise possible explanation of the rise of certification at a common sense level, they do not seem to shed much light on the fundamental dynamics that may be involved. Several theoretical perspectives help make sense of the growth of private standard setting.

First, it is plausible to argue that the programs described above represent a natural, possibly evolutionary process for working out the meaning of policy goals such as sustainable development and ecosystem health. ${ }^{335}$ These ideas can be seen as "master metaphors" having inherent appeal and power. Competition between the systems to give meaning to them is natural, since profound normative decisions are involved and the master metaphors are far from selfdefining. ${ }^{336}$ The growing importance of information and the reliance on expertise also make sense, since equally profound scientific and technical problems are involved.

It is quite reasonable to be suspicious of policy evolution arguments, however. On one hand, more information than in the past is produced by each of the private regulatory programs. On the other, it is less readily available than would be the case with most modern government regulatory programs. Moreover, certain issues, particularly of social justice, get lost in some of the private programs. Arguably, the ISO and AF\&PA programs both operate to mute social

334 See Meetings of the International Forestry Students Association, University of Freiburg, Germany (Sept. 17, 1999).

335 See Giandomenico Majone \& Aaron Wildavsky, Implementation as Evolution, 2 POL. STUD. R. ANN. 103 (1978).

336 See Margaret A. Shannon et al., Science Advocacy is Inevitable: Deal with It (Proceedings of the Society of Am. Foresters, 1996). 
justice concerns, and to de-link them from the environment. These factors raise a second, more traditionally "political" explanation: each of the programs represents a political agenda, and relative political power, rather than social merit, is likely to determine their ultimate success. While political power is obviously an important variable in understanding certification, much of the research on political dynamics completed to date seems to suggest that the certification arena involves new dynamics which are not well understood in terms of traditional political power frameworks. ${ }^{337}$ While it is far from clear why this might be the case, possible explanations include: the effort to use the market as a political arena; constraints imposed by the widespread acceptance of environmental protection as an inherent social goal, and the fact that nation states are not the primary targets of certification politics.

The relative absence of governments from the new regulatory programs raises questions in its own right. One possible explanation is that offered by the environmental NGOs in explaining their decision to set up the FSC: governments had been so ineffective in pursuing the goals of the Rio accords that it was worth establishing an alternative system. ${ }^{338}$ There are several possible explanations for government inactivity. First, governments have faced continuing resource shortages and legitimacy problems in the past two decades, limiting their ability to do much at all. In such circumstances it makes sense for governments to devote their scarce resources to more pressing problems, and ones for which private resources are not available. ${ }^{339}$ Second, there are good reasons to think that governments

E.g., Hoberg, supra note 99; Elliott, Forest Certification, supra note 8.

339 This theory is also consistent with the fact that private initiatives have developed in a number of other areas, including occupational health and safety (see Theo Nichols \& Eric Tucker, Occupational Health and Safety Management Systems in the United Kingdom and Ontario, Canada: A Political Economy Perspective, (No. 21 in the Working Paper Series for the Centre for Research on Work and Society, March 1999)), human rights (see Cassel, supra note 135, and Liubicic, supra note 135), and other areas of environmental protection. There is, 
are inherently more cumbersome policymaking organizations, given their complex procedural rules ${ }^{340}$ and the capacity of negotiations over other issues to block agreement in areas where there is general consensus. This is especially true when numerous governments are involved, as is necessarily the case in global standard setting. These factors can be combined into a kind of "transactions costs" explanation of the growth of private regulatory policymaking: stakeholders can avoid multiple inefficiencies of working through governments by establishing separate vertically and horizontally integrated programs with fewer conflicting interests than governments. ${ }^{341}$ Such programs can take advantage of government policies and legal provisions while avoiding their more cumbersome features.

A transactions cost approach might also help explain the willingness of firms to participate in the programs. Private standards are easier to negotiate than government ones. Also, standardization reduces the costs of doing business. Finally, the programs help reduce public and private liability of corporations and their directors.

\section{Prospects of the Private Environmental Regulatory Programs}

Whether one applies a policy evolution, political power, or transaction cost perspective significantly affects how one sees the

for example, the Marine Stewardship Council which closely parallels the Forest Stewardship Council. Recently Unilever, owner of the Gorton and Birdseye frozen foods brands, agreed to buy only from Marine Stewardship Council certified suppliers by 2005. See Wilson, Uneasy Partnerships, supra note 48.

${ }_{340}$ This is not to say that such procedural rules are undesirable. They have many justifications based on avoiding bad decisions and giving interested parties a chance to offer relevant information and comments.

341 The idea of using transactions costs to understand the forms taken by social organizations was pioneered by Coase, supra note 60 . Its application to public policy frameworks has been rather limited, although Douglass North has applied it very broadly to understanding economic institutions. See DouGLASS C. NORTH, INSTITUTIONS, INSTITUTIONAL CHANGE, AND ECONOMIC PERFORMANCE (1990). 
future prospects of the private environmental regulatory programs. Viewed from a benign evolutionary perspective, the programs are essentially complementary, all sailing down the same broad river of public discourse which no doubt flows toward sustainable development and social justice. As noted above, competition is not inconsistent with this thesis, since it is a common way of defining public ideals. From political power and transactions costs perspectives, however, the systems are competing not just to define norms, but to become long-term institutions for shaping public policy. If that is the case, then organizational resources, among other things, are likely to be central to their success or failure. Table 1 suggests some of the resources that probably would be key and makes rough comparisons among the programs. If all the factors are given equal weight, then the ISO has the clear advantage. However, the weights of the factors are likely to be dynamic, particularly environmental credibility and the capacity to invoke government. Moreover, even if one takes a political power or transaction cost perspective, one cannot discount the importance of actual environmental performance, and that remains to be determined.

Thus, although it is clear that these programs and others will be in competition with each other, it is not possible to predict a particular outcome. It could take one of several forms. First, one program could simply triumph and become a generally accepted world standard, possibly incorporating advantageous features of other programs. Second, the competing programs could create a situation of hopeless mass confusion, constantly undermining and eventually destroying each other. Third, they could continue to mutate and possibly merge into a set of joint ventures. Because each of the programs has significant weaknesses, and because several of them explicitly provide for linkages, this seems to be a likely possibility and there have been some moves in this direction. ${ }^{342}$ But then again,

The British FSC, for example, has recognized the program of the Woodlot Owners Association (See Bass \& Simula, supra note 5, at 33). FSC International is currently engaged in discussions with the Indonesian national certification 
the programs are also at odds with each other, and it may be in the interest of at least some of the programs not to have any single system emerge. This state of affairs could be roughly analogous to the persistence of separate national legal systems despite their gradual convergence toward highly similar substantive requirements. ${ }^{343}$

\begin{tabular}{|c|c|c|c|}
\hline & FSC & ISO & $\overline{\mathrm{AF} \& \mathrm{PA}}$ \\
\hline $\begin{array}{l}\text { Organizational } \\
\text { Capacity }\end{array}$ & Low & High & High \\
\hline Funding and Resources & Low & High & High \\
\hline $\begin{array}{l}\text { Expertise and } \\
\text { Knowledge }\end{array}$ & Medium & High & High \\
\hline $\begin{array}{l}\text { Environmental } \\
\text { Credibility }\end{array}$ & High & $\begin{array}{l}\text { Medium } \\
\text { Low }\end{array}$ & Low \\
\hline $\begin{array}{l}\text { Capacity to Invoke } \\
\text { Government }\end{array}$ & Unclear & High & $\begin{array}{c}\text { Low/ } \\
\text { Medium }\end{array}$ \\
\hline
\end{tabular}

program, the Indonesian Eco-Labelling Institute (LEI). The organizations have agreed to work toward mutual recognition, though that has not occurred. As an intermediate step, FSC has agreed to incorporate indicators and criteria developed by LEI in FSC certification proceedings. See GTZ, Newsletter, supra note 162, at 5. Efforts to achieve a merger between FSC Canada and the Canadian Standards Association program, which is roughly comparable to SFI, failed after a number of attempts in the mid-1990s. See Elliot, Forest Certification, supra note 8, at 31012.

343 I am indebted to David Westbrook for this suggestion. 


\section{Important Questions}

The above discussion of prospects does not imply that private environmental regulatory programs are immune from effective analysis and critique. Indeed, how they fare over time is likely to depend significantly on how they are understood to affect society and the environment. The programs face a number of significant questions. The first set, concerning their effects on environment, human rights, and community, were probed in the body of the article. It reached the general conclusion that all of the programs are likely to lead to environmental improvements in the near and mid term, but that only the FSC program would bring significant gains to human rights and community. The ISO and AF\&PA programs seek to delink those issues from environment. On their own terms they operate to narrow the forums for human rights and community mobilization. However, because human rights are pursued in many arenas by many organizations, it is not clear that they will operate to reduce human rights or consideration for communities in forest management. It is clear, however, that any gains the ISO and AF\&PA programs might bring to human rights and community concerns will be limited to the indirect consequences of improved environmental management.

\section{Equity}

Private environmental regulatory programs face a number of difficult and increasingly important questions of social equity. Certification programs are of course designed to discriminate between desirable and undesirable industry practices. Problems arise, however, because undesirable practices may be correlated with other features of the social landscape which the programs do not necessarily wish to discriminate against - such as how small a firm is, or whether it is located in a developing country. Equity issues such as these are likely to become more apparent and important in the next few years, and certification programs will probably have to focus an 
increasing amount of their deliberative capacity on them. The issues come in two general, often interrelated forms: disparate outcomes and disparate participation in decision making. ${ }^{344}$

Outcome issues include the following. First, because they are relatively technocratic and management-intensive, certification programs have a built-in tendency to favor large companies, which enjoy economies of scale in employing specialists, implementing information systems, and the like. Large companies also generally enjoy superior access to information about existing and likely certification requirements, to the investment capital often necessary to meet them, and to markets in industrialized countries. Companies with integrated production, distribution, and retail systems are likely to be much more successful in profiting from certified products than those involved only in production, since any "premium" paid for certified products comes from the ultimate consumer. Thus there have been some indications that primary producers in developing countries often receive no price advantage in selling certified wood. ${ }^{345}$

Second, and perhaps more vexingly, the stricter that environmental standards become, the greater the disparity between the abilities of large, sophisticated corporations and small, often third world businesses to meet them. Certification systems tend to favor bureaucratic over traditional management systems, forests with developed management policies over ones that are just being brought under organized forestry, forests with clearly worked out tenure systems over those with unsettled ones, and quite possibly production

These issues were perceptively sketched in Chris Elliott \& Virgilio M. Viana, Potential Inequalities and Unintended Effects of Certification, in VIRGILIO VIANA ET AL., CERTIFICATION OF FoREST PRODUCTS: IsSUES AND PERSPECTIVES (1996). They are more fully explored in Thornber, Equity and Certification, supra note 18. Both articles make most of the points mentioned in this section. It should also be noted that although the certification programs face these issues, they are not fundamentally different from public regulatory agencies in this regard. Any transnational public regulatory program would be at least as afflicted by equity problems.

345 See Elliott \& Viana, supra note 344. 
forests over "natural" ones. ${ }^{346}$ They also favor forests managed solely for wood production, and have a hard time dealing with mixed landuse, rural livelihood systems combining farming and forestry. ${ }^{347}$ Timber harvested from lands converted from forestry to agriculture is not eligible for certification, even though conversion might be appropriate in many developing countries. ${ }^{348}$ The great majority of accredited certifiers in all systems are based in northern countries. ${ }^{349}$ The knowledge base for achieving certification standards has largely been developed in northern countries, and is most readily accessible there. ${ }^{350}$ All of the favored elements are disproportionately located in developed countries and the disfavored ones in developing countries.

In sum, these factors add up to considerable advantage for actors in developed countries over those in southern countries. These concerns are currently the focus of much discussion in forest certification circles. The FSC, for example, has convened an effort to make certification more accessible to small businesses. ${ }^{351}$ An underlying purpose of that effort is to make it more accessible to tropical countries. There is also a considerable amount of discussion in certification circles regarding whether initial standards for certification should be made lower in developing countries, with the expectation that they would be raised as the capacity to meet them

346 What constitutes a "natural" forest is a difficult question in itself. For present purposes, it is sufficient to say that it is a forest that has not been devoted to organized timber production.

347 See Thornber, Equity and Certification, supra note 18, at 22-23.

$348 \quad$ See id. at 20.

349 See supra text accompanying notes 35-37. As implied above, there may also be hidden, "micro-equity" problems because of disparate application of standards by different certifiers, but evidence on this issue is very limited and will take some time to develop.

350 Thomber also notes that few incentives work in favor of widespread sharing of knowledge, although some certifiers are now trying to facilitate the sharing of knowledge. See Thornber, Equity and Certification, supra note 18, at 3839.

35! See Scrase, supra note 52. See also discussion infra at notes 53-60. 
rose. ${ }^{352}$ It is not easy to explain how this policy would fit with the principle of a uniform standard for all forests, however. Thus, solving these problems will be a difficult and extended process.

The process will be more difficult because most of most of the decisional processes in certification programs are dominated by the same interests that receive the most benefit from them - large enterprises based in and seeking to satisfy consumers in northern countries. This is not uniformly the case, of course. The FSC, in particular, has established its headquarters in Mexico, gives equal power to social, environmental, and economic interests, and has restructured itself to give equal power to northern and southern interests. Most of its core policies, however, were formed when it was dominated more by northern interests. Even now, both the social chamber and the south can be characterized as severely underrepresented. ${ }^{353}$ The FSC represents the best case for equity of the major private certifiers. While the ISO has many developing country members, they tend to participate less and to be less effective in policymaking and standard setting than those from developed countries. The AF\&PA does not include either small businesses or developing countries in its decision making processes. Its European counterpart, the PEFC, incorporates small businesses, but still limits decision making to northern interests.

Given the overall incentives for environmental certification systems to operate on a global scale, it seems essential for them to incorporate effectively both developed and developing countries. Many of the equity issues noted above are likely to be central to that process. But it is hard to say for sure. Two of the three systems discussed in this article are not overly concerned with equity issues, and there is no obvious reason to assume they are making a serious

352 E.g., Bass \& Simula, supra note 5, at 27; Thornber, Equity and Ceritification, supra note 18, at 19-20.

353 In September 1999, only 17\% of FSC members were in the social chamber, and only $27 \%$ of the total membership was from the south. See Thomber, Equity and Cerification, supra note 18, at 34. 
mistake. Given the market-driven elements of certification, they may simply be betting that consumer demand will focus more on the physical quality of the production environment than on its social quality. This remains to be seen. If there is indeed a larger sense of justice at work here, which is not satisfied through other mechanisms, then they may indeed be wrong. ${ }^{354}$

\section{Law}

Although the private environmental regulatory systems discussed in this article are officially separate from formal legal systems, they necessarily interact with them, and are likely to do so increasingly in the future. This is so because private regulatory programs are essentially parallel regulatory systems. The standards they set and the institutions they create can augment, displace, or conflict with legal regulation. Governments will therefore have to make choices regarding how to deal with private regulatory systems. They could ignore them, of course. But even if they do, private standards are likely to bleed into legal systems through such avenues as best management practices requirements in regulatory systems, tort liability standards, truth in advertising laws, suits for misrepresentation, equitable judicial remedies for regulatory violations, and the like. ${ }^{355}$

It is interesting to note that the individual principles, standards, and criteria used in the private regulatory systems seem markedly different from the rules typically produced by public regulatory systems. They do not seek to define acceptable and unacceptable behavior in nearly as much detail, nor to eliminate as much of the appearance of discretion, as public regulatory rules

354 For an prescient exposition on the potential power of perceptions of justice, see EDMOND CAHN, THE SENSE OF INJUSTICE (1964). The recent literature on environmental justice is voluminous, and cannot be represented here.

355 For preliminary reviews, see Webb, supra note 262; Meidinger, Incorporating Certification Systems, supra note 132. 
typically do. They explicitly allow for professional judgment and balancing in site specific conditions. This may give them a significant advantage in complex environments where new information is constantly being produced and alternative management strategies proposed.

Because of their potentially higher performance requirements and greater adaptability, privately set standards could be attractive to government legal systems, which could adopt either specific standards or entire certification systems, and make them obligatory. In doing so, they might have to choose one system over the alternatives. Either in conjunction with such a move, or separately, governments could undertake to regulate the operations of the private regulatory systems, setting requirements for rule-making, enforcement, certifier qualifications, and the like. ${ }^{356}$

It is also possible that significant conflicts will emerge between private standard systems and governmentally based laws. The most immediate potential for such conflict is in the rapidly changing area of international trade law. Treaties administered by the World Trade Organization seek to eliminate "non-tariff barriers to trade." Particularly suspect are rules distinguishing among "like" products based on how they were produced, which is arguably what the environmental certification systems do. Although the primary targets of the international trade laws are governmentally set standards, there is serious discussion about whether and when

Meidinger, Incorporating Certification Systems, supra note 132; Rametsteiner, supra note 129, at 199-203. It is worth noting that many other certification systems are regulated by governments. The Department of Agriculture, for example, is in the process of promulgating new standards for organic foods. $<\mathrm{http}: / / w w w . a m s . u s d a . g o v / n o p>$. On the other hand, it is also true that regulating in this area can be very tricky, as the FTC discovered when it attempted to regulate advertising for "natural" and "organic" foods in the 1970s. See Barry Boyer, Funding Public Participation in Agency Proceedings: The FTC Experience, 70 GEORGETOWN L. J. 51-172 (1981). 


\section{BUFFALO ENVIRONMENTAL LAW JOURNAL [Vol 7}

privately developed standards should be addressed. ${ }^{357}$ Moreover, as noted above, private standards are likely to infuse public ones in various ways, and as they do they are more likely to come under WTO strictures. Not all private standards appear equally vulnerable to international trade laws, however. The WTO has conferred a presumptive acceptability and preference on the ISO system, primarily on grounds that every trading country can participate in the standard setting process and that resultant standards are consensual. ${ }^{358}$ Accordingly, the other private systems are at a disadvantage vis a viz the ISO system, and may experience significant pressures to align themselves with it.

Nationally based trade regulation laws also have some potential to create problems for private regulatory systems, as noted in the discussion of the AF\&PA's logger training program. ${ }^{359}$ The U.S. antitrust laws, for example, prohibit "every contract, combination ... or conspiracy, in restraint of trade or commerce" and all attempts and conspiracies to "monopolize any part of the trade or commerce" as well as successful monopolization without defining key terms such as "restraint of trade" or "monopolize. ${ }^{1360}$ Because the standard setting systems seek to channel trade to certified businesses, restraint of trade allegations are possible. It does not appear likely,

357 E.g., Webb, supra note 262, at 40-41. See also Natural Resources and Ethical Trade Program, Forest Certification in the Eyes of the World Trade Organisation: (implications of the Seattle Round), <http://www.nri.org/NRET/PWB/et1-0.htm>.

358 E.g., Hauselmann, supra note 187 , at 6.

359 See supra text accompanying note 310.

360 See Sherman Antitrust Act, 15 U.S.C. $\$ \$ 1-37 a$. 
however, that the systems as currently constituted will face serious anti-trust problems. ${ }^{361}$ Indeed, it appears that they have been alert to potential problems and tried to avoid them. ${ }^{362}$

In addition, as noted above, private inspection and certification systems face challenges of consistency and reliability which have been major problems for public regulatory systems. ${ }^{363}$ If it turns out over time that there are significant differences between operations certified as being comparable, for example, then legal suits for misrepresentation are possible, setting up a number of discrete conflicts between private regulation and legal systems, and potentially triggering efforts by public legal systems to regulate private ones. ${ }^{364}$

Finally, certification programs entail some potentially fascinating experiments in grand legal theory. In attempting to incorporate environmental, human rights, community, and economic values in a single set of globally applicable standards, for example, the FSC would seem to be assuming that it is possible to do so. Few modern legal scholars would be so bold. Most would assume that the complexities of the world and tensions among the incorporated values must eventually force fractures and consequent political choices. ${ }^{365}$ Still, it will be interesting to see where this intrepid experiment of optimistic environmentalists and social reformers may lead.

361 See Sharon Prise, Sustainable Forestry and Buyers Groups: Protecting Our Resources Without Restricting Free Trade (Independent Study Paper, State University of New York at Buffalo, 1998) (on file with author); Robert Heidt, Industry Self-Regulation and the Useless Concept of 'Group Boycott' 39 VAND. L. R. 1507 (1986).

362 Personal communications.

363 See supra text accompanying notes 83-93.

364 See Webb, supra note 262; Meidinger, Incorporating Certification Systems, supra note 132.

365 For a simple illustration of the problem, see S. James Anaya, supra note 143. 


\section{Democracy}

The possibility that private standard setting may amount to a form of non-governmental law making leads directly to questions of democratic legitimacy. The private systems operate largely outside governmental law-making systems. Many of them work on a transnational level, thereby racing around governmental processes usually used to test the legitimacy of regulatory concepts and practices. These developments inevitably shift decisional power from some sectors of society to others, though which ones will actually enjoy increased influence depends in part on how private standard setting fares in the future. Depending on which system prevails, different types of interests will enjoy increased power. If the ISO system prevails, for example, it seems clear that transnational corporations will probably have succeeded in expanding their role in public governance. If the FSC system prevails, environmental groups and other social interests will enjoy increased power. All of the scenarios seem to benefit professional experts. At this stage of their development, private regulatory systems do not seem to bode well for public participation. Even if participation has never been what it was cracked up to be in governmental regulatory systems, most of the private systems purposely constrict participation and make it secondary to business and professional decision making.

Even if these developments are occurring, their implications for democracy are not self-evident. One view is that private environmental regulatory initiatives are efforts by narrow interests to short-circuit political processes, seize control of the standard setting agenda, and close off probing public review and critique of the standards as implemented. ${ }^{366}$ Thus, stakeholder groups are strategically chosen, decisions made, and then the process "goes public" only after key issues are off the table. Conversely, it is possible to argue that the growth of private standard setting is not 
anti-democratic. First, most governmental systems are no more democratic in practice than some of the certification systems. Second, the very existence of the new systems reflects widespread social agreement on fundamental principles. Private regulation is simply an efficient mechanism for implementing goals established through democratic processes. Not everyone can participate in regulatory decision making in any case, and these systems can be seen as including, or seeking to include, the participants necessary to adequately serve society's interests. Moreover, the fact that private standard setting processes might compete to some extent with public ones is not bad. Controlling who makes a decision is no guarantee of a good, or even a democratic decision except in a purely formal theory of democracy. Social deliberation always occurs in many forums other than government, and it may be good for governmental regulatory systems to have to compete with non-governmental ones. Thus society at large might be understood as running a competition among regulatory systems, ${ }^{367}$ and the debate they are conducting might be understood as an expansive social dialogue on how forests should be managed. ${ }^{368}$

Determining which of these views of democratic legitimacy should prevail will itself require a broad public debate. That debate must be informed by expertise and a considerable amount of independent research, but cannot be limited to the narrow communities represented by the private regulatory systems described

See Colin Scott, Institutional Competition and Coordination in the Process of Telecommunications Liberalization, in INTERNATIONAL REGULATORY COMPETITION AND COORDINATION: PERSPECTIVES ON ECONOMIC REGULATION IN EUROPE AND THE UNITED STATES 382-413 (William Bratton et al. eds., 1996). Of course, this process itself could reflect a major institutional reconfiguration, which itself will need to be understood.

368 Bass \& Simula argue that the discussion is creating widespread agreement on the issue. See Bass \& Simula, supra note 5, at 22. 


\section{BUFFALO ENVIRONMENTAL LAW JOURNAL [Vol 7}

in this article. The debate will take time, and may not even have begun as this article is published. It might very well reach the conclusion, based on watching the systems develop for a while, that the certification programs were a good thing in their first decade, but need to be reshaped by other social institutions in their second. 